\title{
A RELAÇÃO ENTRE CIRURGIÕES-DENTISTAS E AS OPERADORAS DE PLANOS DE SAÚDE NO MUNICÍPIO DE BAURU - SP
}

Haroldo José Mendes

Dissertação apresentada à Faculdade de Odontologia de Bauru, da Universidade de São Paulo, como parte dos requisitos para obtenção do título de Mestre em Odontologia, área de Ortodontia e Odontologia em Saúde Coletiva - opção Odontologia em Saúde Coletiva.

(Edição Revisada)
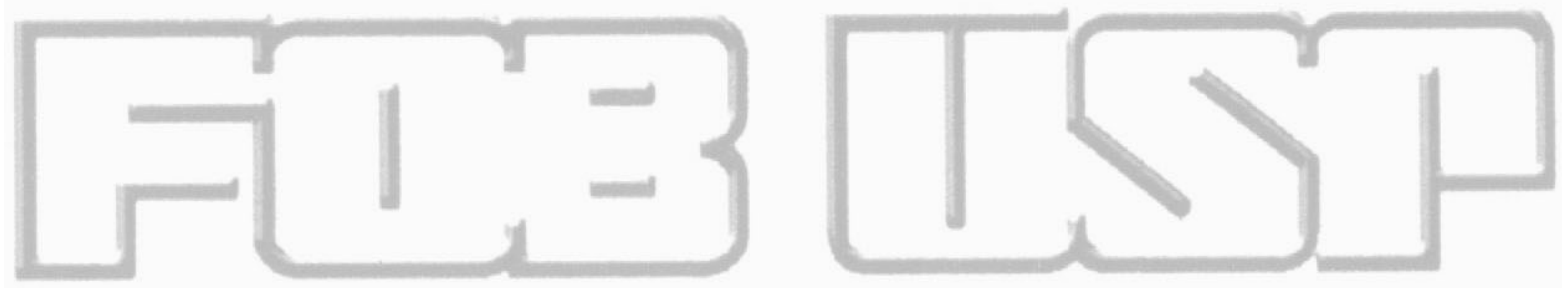

B A U R U

2005 


\title{
A RELAÇÃO ENTRE CIRURGIÕES-DENTISTAS E AS OPERADORAS DE PLANOS DE SAÚDE NO MUNICÍPIO DE BAURU - SP
}

Haroldo José Mendes

\begin{abstract}
Dissertação apresentada à Faculdade de Odontologia de Bauru, da Universidade de São Paulo, como parte dos requisitos para obtenção do título de Mestre em Odontologia, área de Ortodontia e Odontologia em Saúde Coletiva - opção Odontologia em Saúde Coletiva.
\end{abstract}

(Edição Revisada)

Orientador: Prof. Dr. José Roberto de Magalhães Bastos

B A U R U

2005 

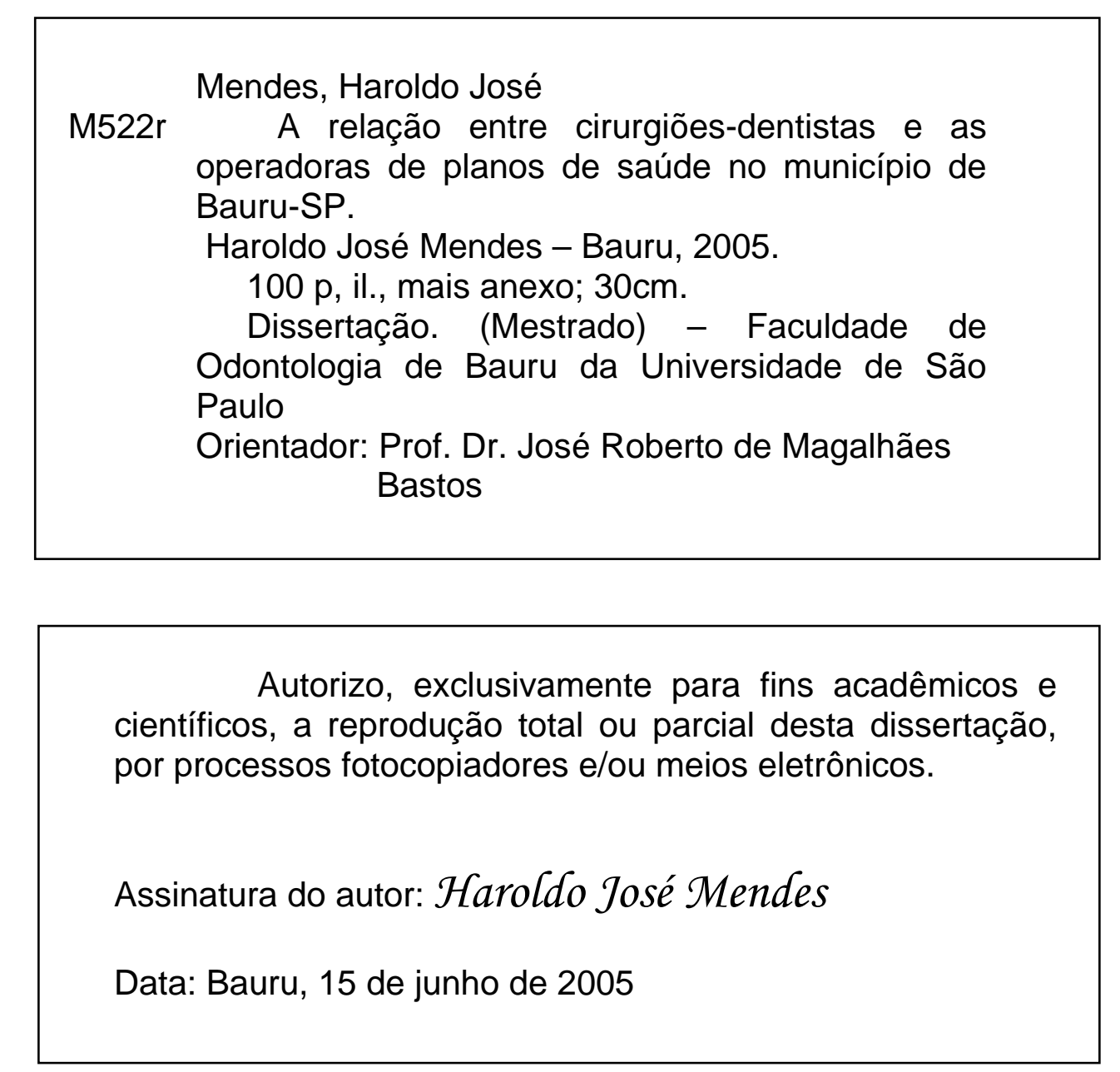

Projeto de pesquisa aprovado pelo Comitê de Ética em Pesquisa da Faculdade de Odontologia de Bauru, Universidade de São Paulo, na reunião do dia 28 de abril de 2004. Protocolo n. ${ }^{\circ} 43 / 2004$ 


\section{Universidade de São Paulo \\ Faculdade de Odontologia de Bauru}

Al. Dr. Octávio Pinheiro Brisolla, 9-75 - Bauru-SP - CEP 17012-901 - C.P. 73

PABX (0XX14)235-8000 - FAX (0XX14)223-4679

Pos-Graduafão

e-mail: posgrad@fob.usp.br - Fone: (0XX14)235-8223

\section{FOLHA DE APROVAÇÃO}

Dissertação apresentada e defendida por

HAROLDO JOSÉ MENDES

e aprovada pela Comissão Julgadora

em 28 de fevereiro de 2005.

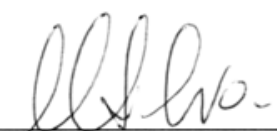

Prof. Dr. MOACYR DA SILVA

Faculdade de Odontologia - USP

Prof. Dr. ARSENIO SALES PERES

Faculdade de Odontologia de Bauru - USP

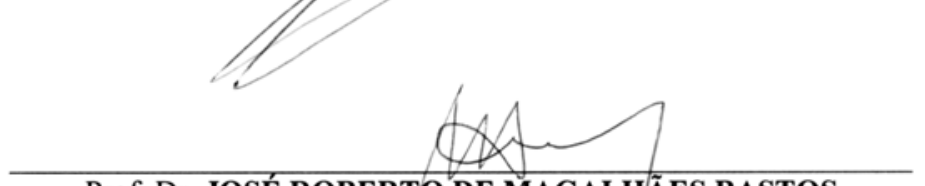

Prof. Dr. JOSÉ ROBERTO DE MAGALHÃES BASTOS

Presidente da Banca

Faculdade de Odontologia de Bauru - USP

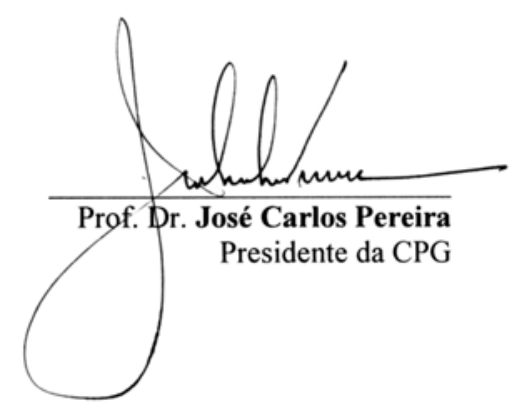




\section{HAROLDO JOSÉ MENDES}

Nascimento

Filiação

$1995-1998$

$2000-2001$

$2003-2005$

2004

Associações
25 Julho de 1972

Bauru-SP

Dirce Nogueira Mendes

Haroldo Walter Mendes \&

Curso de Graduação em Odontologia, Faculdade de Odontologia de Bauru - USP

Curso de Especialização em Odontologia em Saúde Coletiva pelo Hospital de Reabilitação e Anomalias Craniofaciais, HRAC/USP

Curso de Pós-Graduação em Odontologia em Saúde Coletiva, nível de Mestrado, na Faculdade de Odontologia de Bauru - USP

Professor Substituto do Departamento de Odontologia em Saúde Coletiva da Universidade Federal da Bahia

Cirurgião-Dentista do PSF de Vitória da Conquista - BA

ABENO - Associação Brasileira de Ensino Odontológico ABRASCO - Associação Brasileira de Saúde Coletiva 
À minha mãe, minha grande amiga, um exemplo de otimismo, perseverança e força, que sempre está ao meu lado.

À minha esposa Patrícia, meu norte nos momentos de tempestade e grande parceira nas alegrias.

À minha irmã e ao meu sobrinho Gabriel, pessoas muito especiais em minha vida.

A Deus, por me presentear com esta família. 


\section{Ao Prof. Dr. José Roberto de Magalhães Bastos}

pelo respeito e otimismo com que sempre me orientou. Agradeço também pela confiança em mim depositada e pela seriedade com que realiza os trabalhos. Por me fazer perceber a importância do "ser Mestre".

Aos demais professores do departamento de Odontologia em Saúde Coletiva da FOB - USP, Prof. Dr. José Roberto Pereira Lauris, Prof. Dr. Vitoriano Truvijo Bijella, Prof. Dr. Ernesto Pilloto Gomes de Medeiros, Prof. Dr. Arsenio Sales Peres e Prof. ${ }^{a}$ Sílvia Helena de Carvalho Sales Peres, pelos ensinamentos transmitidos.

À todos professores e funcionários da Faculdade de Odontologia de Bauru (FOB-USP) pelo carinho, dedicação e respeito que tiveram comigo desde que entrei pela primeira vez na FOB.

À Silvia do departamento de Saúde Coletiva, pelo carinho e pelas inúmeras vezes que se dispôs a me ajudar. 
Às demais funcionárias e amigas do departamento de Saúde Coletiva, Marta, Helena e Rosa pelos alegres dias de convivência.

Aos funcionários da Biblioteca e da Pós-Graduação, pela dedicação e paciência com que nos atende.

À todos os participantes deste trabalho, que contribuíram com a permissão das entrevistas.

Aos meus sempre amigos Sadam, Fábio, Balan, Jordy, Járcio e Juriti pelo companheirismo e amizade.

A todos os amigos que conquistei nessa trajetória.

Ao meu colega de mestrado, Ricardo, que começou como simples colegas, mas hoje posso dizer que é meu amigo. Agradeço pelo companheirismo e pelos momentos compartilhados. Com certeza ainda teremos muitos juntos! 
Finalmente, a todos que direta ou indiretamente contribuíram para a realização deste trabalho, pois sempre acabamos esquecendo de alguém, não menos importante que os demais. 


\section{SUMÁRIO}

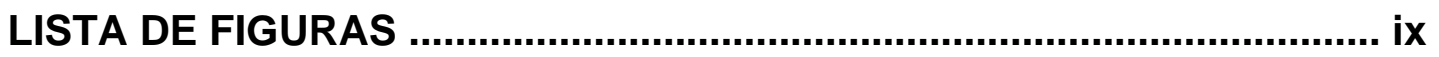

LISTA DE ABREVIATURAS ...................................................................

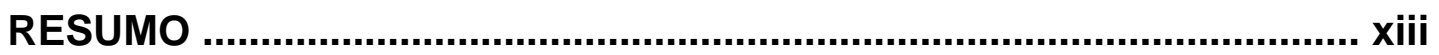

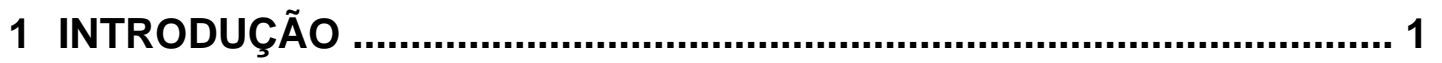

2 REVISTA DA LITERATURA

2.1. Saúde Suplementar.......................................................... 10

2.2. A Prática Odontológica …................................................. 28

3 OBJETIVOS

3.1 Objetivo Geral .............................................................. 47

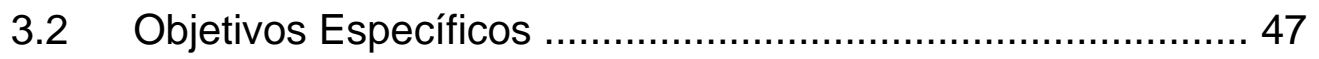

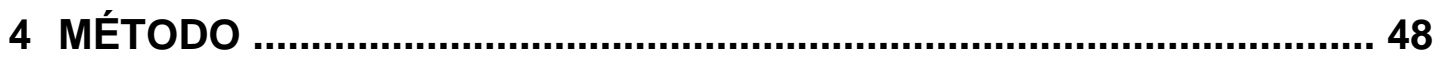

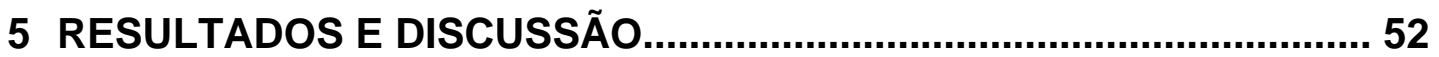

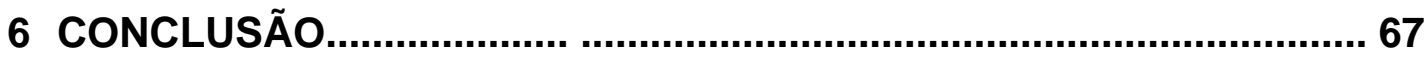

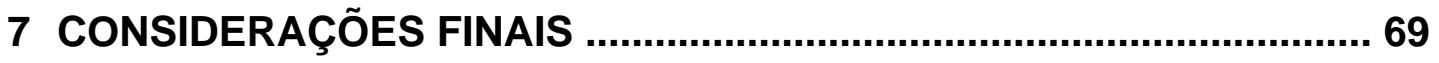

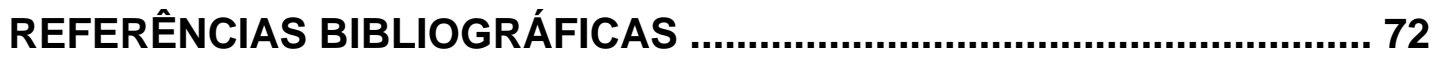

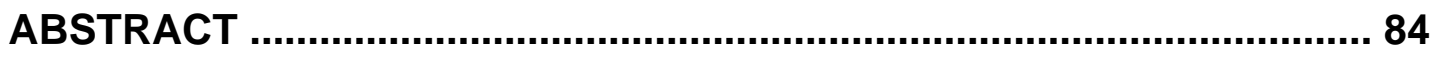

ANEXOS

Anexo I - Carta de Aprovação do CEP

Anexo II - Termo de Consentimento Livre e Esclarecido

Anexo III - Roteiro de Entrevista 


\section{LISTA DE FIGURAS}

Tabela 1 - Distribuição dos odontólogos entrevistados no município de Bauru, SP, segundo vínculo com as operadoras de planos de saúde, 2004

Tabela 2 - Operadoras de planos de saúde citadas pelos odontólogos entrevistados no município de Bauru, SP, 2004

Tabela 3 - Distribuição dos odontólogos entrevistados no município de Bauru, SP, segundo motivo do não credenciamento às operadoras de planos de saúde, 2004 .56

Tabela 4 - Distribuição dos odontólogos entrevistados no município de Bauru, SP, segundo motivo do credenciamento às operadoras de planos de saúde, 2004. .58

Tabela 5 - Distribuição dos odontólogos entrevistados no município de Bauru, SP, segundo a situação do fluxo da clientela particular no consultório após o credenciamento às operadoras de planos de saúde, 2004. .58 
Tabela 6 - Distribuição dos odontólogos entrevistados no município de Bauru, SP, segundo a satisfação quanto as tabelas de valores utilizadas pelas operadoras de planos de saúde, 2004

Tabela 7 - Distribuição dos odontólogos entrevistados no município de Bauru, SP, segundo a satisfação quanto ao vínculo com as operadoras de planos de saúde, 2004 62

Tabela 8 - Distribuição dos odontólogos entrevistados no município de Bauru, SP, segundo sua opinião sobre a existência ou não de interferência das operadoras de planos de saúde nos planos de tratamento, 2004 63

Tabela 9 - Distribuição dos odontólogos entrevistados no município de Bauru, SP, segundo sua avaliação quanto aos prazos de pagamento dos procedimentos pelas operadoras de planos de saúde, 2004 .65

Tabela 10 - Distribuição dos odontólogos entrevistados no município de Bauru, SP, segundo a representação da remuneração pelas operadoras de planos de saúde na renda mensal do consultório, 2004. .66 


\section{LiSTA de AbreViaturas e Siglas}

ABH - Associação Brasileira de Hospitais

ABO - Associação Brasileira de Odontologia

ABRAMGE - Associação Brasileira de Medicina de Grupo

ADA - Agência de Desenvolvimento da Amazônia

AMB - Associação Médica Brasileira

ANA - Agência Nacional de Águas

ANATEL - Agência Nacional de Telecomunicações

ANEEL - Agência Nacional de Energia Elétrica

ANP - Agência Nacional de Petróleo

ANS - Agência Nacional de Saúde

ANS - Agência Nacional de Saúde Suplementar

ANTT - Agência Nacional de Transportes Terrestres

ANVISA - Agência Nacional de Saúde Suplementar

CAP - Caixa de Aposentadorias e Pensões

CESP - Companhia Energética de São Paulo

CFO - Conselho Federal de Odontologia

CNAS - Conselho Nacional de Assistência Social

CNSP - Conselho Nacional de Seguros Privados

CONSU - Conselho Nacional de Saúde Suplementar

CRO - Conselho Regional de Odontologia

CROSP - Conselho Regional de Odontologia de São Paulo

DESAS - Departamento de Saúde Suplementar 
EMBRATEL - Empresa Brasileira de Telecomunicações

FBH - Federação Brasileira de Hospitais

FUNASA - Fundação Nacional de Saúde

FUNCEF - Fundação da Caixa Econômica Federal

IAP - Instituto de Aposentadorias e Pensões

IAPI - Instituto de Aposentadorias e Pensões dos Industriários

IBGE - Instituto Brasileiro de Geografia e Estatística

INAMPS - Instituto Nacional de Assistência Médica e Previdência Social

INPAO - Instituto de Previdência e Assistência Odontológica

INPS - Instituto Nacional da Previdência Social

MP - Medida Provisória

OMS - Organização Mundial de Saúde

PNAD - Pesquisa Nacional por Amostra de Domicilios

PPA - Plano de Pronta Ação

RDC - Resolução de Diretoria Colegiada

SAS - Secretaria de Assistência à Saúde

SESP - Serviço Especial de Saúde Pública

SP - São Paulo

SUCAM - Superintendência de Campanhas de Saúde Pública

SUDS - Sistema Unificado e Descentralizado de Saúde

SUS - Sistema Único de Saúde

SUSEP - Superintendência de Seguros Privados

USP - Universidade de São Paulo 
Resumo 


\section{RESUMO}

Desde o inicio da história dos planos de saúde no Brasil, eles existiram sem nenhuma regulamentação. Vários desequilíbrios entre as empresas que oferecem os planos, os prestadores de serviços e seus usuários foram detectadas ao longo do tempo. A Agência Nacional de Saúde Suplementar veio com o objetivo de promover a defesa do interesse público, regulando as operadoras. Com a caracterização da Assistência Odontológica Suplementar surgiram as empresas odontológicas, cujo principal objetivo parece ser obter o maior lucro possível num mercado de serviços onde há muitos cirurgiões-dentistas e um grande número de pessoas sem acesso ao atendimento. O profissional vê esses acontecimentos como uma oportunidade de aumentar sua clientela e seu faturamento, acarretando talvez, numa busca frenética por convênios que nem sempre proporcionam condições ideais para a prática da odontologia liberal. Diante disso, esse estudo se propôs a identificar, na cidade de Bauru-SP, a quantidade de profissionais que são conveniados a operadoras de planos de saúde odontológica e quais delas atuam na cidade além de avaliar o grau de satisfação dos credenciados, através de um questionário direcionado a 91 profissionais escolhidos por conveniência. Os resultados mostram grande parte dos profissionais são conveniados ou estão esperando uma oportunidade para fazê-lo. Foram citadas 14 operadoras que atuam no município, mas acredita-se que existam outras que não foram citadas devido a composição da amostra e da não participação de muitos 
profissionais. Aumentar rendimentos e ter um fluxo de pacientes maior e garantido parecem ser as supostas vantagens que fazem com que inúmeros profissionais procurem se relacionar com as operadoras de planos de saúde. Os profissionais estão satisfeitos em se relacionar com as operadoras. A crise no modelo liberal da profissão, representada por consultórios particulares, deverá exigir desses profissionais uma reavaliação na forma de organização e filosofia de atendimento. As mudanças que se delineiam para o futuro no mercado odontológico devem considerar a participação decisiva da chamada odontologia suplementar representada pelas operadoras. Cabe a todos uma maior integração, resultando assim em maior qualidade do atendimento e dos serviços prestados, e na elevação do grau de satisfação dos consumidores. 
1 Introdução 


\section{INTRODUÇÃO}

A questão dos planos de saúde no Brasil tem sido bastante discutida nos últimos anos. Vários desequilíbrios nas relações entre as empresas que ofertam planos de saúde, os prestadores de serviços e seus usuários foram detectadas ao longo do tempo. Desta forma, havia uma certa pressão por parte da sociedade para que este setor fosse regulamentado, bem como a exigência de regulamentação contemplada na revisão constitucional de $1988^{3,28,37,51}$

A história destes planos se inicia nos anos 60 , na região do $A B C^{*}$ Paulista, por meio da demanda de empresas desta região que queriam oferecer assistência médica aos seus funcionários. ${ }^{28,50} \mathrm{~A}$ partir daí, foram quase quarenta anos de existência destas empresas sem nenhum tipo de regulamentação específica. Tal discussão foi parar no Congresso Nacional por meio de vários Projetos de Lei apresentados na Câmara dos Deputados e no Senado Federal. Estes ficaram tramitando por quase dez anos. ${ }^{50} \mathrm{Em} 03$ de junho de 1998 foi sancionada a Lei n. $^{\circ} 9656^{17}$, que dispõe sobre os Planos Privados de Assistência à Saúde. No entanto, no dia seguinte, esta mesma Lei foi alterada por uma Medida Provisória n. ${ }^{\circ} 1665^{19}$ apresentando mudanças em diversos dispositivos da referida Lei. Na época, as MPs, de acordo com a legislação, eram vigentes por apenas 30 dias. Após esse prazo, ou a MP deveria ser convertida em Lei, ou deveria ser

\footnotetext{
* Sigla pela qual é conhecida a região dos municípios altamente industrializados de Santo André, São Bernardo do Campo e São Caetano do Sul, no Estado de São Paulo
} 
republicada. E foi o que ocorreu, a Lei n. ${ }^{\circ} 9656^{17}$ acabou sendo alterada por 44 MPs, sendo que, a cada reedição, mais mudanças no texto da Lei ocorriam. Por força de uma emenda constitucional, então aprovada no Congresso, as Medidas Provisórias editadas passaram a ter validade até o pronunciamento do Legislativo, dispensando reedição.

A Agência Nacional de Saúde Suplementar (ANS) foi criada em novembro de 1.999 através da MP $n^{0} 1.928^{20}$, aprovada pelo Congresso Nacional e convertida na Lei $\mathrm{n}^{0} 9.961^{18}$, de 28 de janeiro de 2000, a ser constituída e com sede prevista na cidade do Rio de Janeiro. Esta autarquia especial tem por finalidade institucional promover a defesa do interesse público na assistência suplementar à saúde, regulando as operadoras setoriais, inclusive quanto às suas relações com prestadores e consumidores, contribuindo para o desenvolvimento das ações de saúde no país. Todos os procedimentos de normatização, fiscalização e controle das operadoras de planos privados de assistência à saúde são de competência da ANS .

A Lei . $^{\circ} 9656 / 98^{17}$, quando editada, tinha como foco principal os planos médico-hospitalares e, portanto, praticamente todos os seus dispositivos foram direcionados a este segmento e a intenção era reequilibrar as relações no mercado de saúde suplementar. Entretanto, algumas especificidades dos planos odontológicos não foram devidamente contempladas na regulamentação. Esses estão sob o manto regulatório da Lei, mas foram tratados como se fossem planos médico-hospitalares. 
Após dois anos e meio de regulação, as diferenças entre os planos odontológicos e os planos médico-hospitalares começaram a aparecer, sinalizando a necessidade de um conhecimento aprofundado sobre a estrutura de funcionamento deste mercado. ${ }^{51}$

A Odontologia no Brasil é uma assistência predominantemente privada e, segundo Pesquisa Nacional por Amostra de Domicílios (PNAD) ${ }^{35}$, realizada pelo Instituto Brasileiro de Geografia e Estatística (IBGE), cerca de 29 milhões de brasileiros nunca receberam nenhum tipo de assistência odontológica. A cobertura e a abrangência da assistência bucal oferecidas pelo setor público ainda são incipientes.

Melhorar os índices de saúde bucal significa, na prática, que cada vez mais as pessoas têm mantido seus dentes na boca, isto é, a quantidade de dentes perdidos tem diminuído. Seguindo este raciocínio, quanto mais as pessoas mantêm seus dentes, mais ficam expostos a doenças bucais. Ou seja, mais e mais pessoas necessitam de atenção odontológica. Enfim, pode-se imaginar que a demanda por assistência odontológica tende a aumentar, em função de mudanças no perfil populacional. ${ }^{2,6,50}$

Uma característica peculiar do Brasil é a quantidade de cirurgiõesdentistas que existem no mercado. Hoje, são mais de 170 mil cirurgiõesdentistas, mais profissionais que o Canadá e os Estados Unidos juntos. ${ }^{23,58}$ No entanto, o índice de saúde bucal não é melhor que o desses países. Apesar de existirem 29 milhões de brasileiros que nunca foram a um cirurgião-dentista ${ }^{34}$, a classe têm reclamado sobre a ociosidade de seus consultórios, que não há mais pacientes. Segundo dados do $\operatorname{IBGE}^{34}$, a 
classe que mais consome serviços odontológicos é a classe com renda superior a nove salários mínimos. Entretanto, aí se encontra cerca de apenas $5 \%$ da população. ${ }^{34}$ É neste contexto que entra em cena as operadoras de planos odontológicos, empresas que comercializam assistência odontológica e que atuam num mercado de serviços onde há muitos cirurgiões-dentistas sem condição de desenvolver uma prática profissional satisfatória e um número grande de indivíduos sem acesso ao atendimento odontológico. ${ }^{2,6,50} \bigcirc$ principal objetivo desse tipo de intermediário é obter o maior lucro possível numa situação em que há de um lado, os pobres, que formam a base da pirâmide social brasileira, e de outro, os cirurgiões-dentistas, que necessitam garantir sua sobrevivência em um mercado de trabalho saturado. ${ }^{31,55,59}$

As características dos planos odontológicos têm sido pouco estudadas no Brasil quando comparadas à quantidade de estudos desenvolvidos referentes a planos médico-hospitalares. Uma explicação pode ser o fato das doenças bucais e da organização da oferta de saúde bucal sempre terem sido entendidas com características próximas às da saúde como um todo. No entanto, isto não é inteiramente correto, uma vez que a odontologia possui peculiaridades que a diferem da medicina e, portanto, tornam os planos odontológicos diferentes dos planos médicos, principalmente no que se refere a aspectos operacionais. ${ }^{2}$

As doenças bucais podem ser resumidas em principalmente duas: cárie e periodontopatias. ${ }^{42,} 46$ Já na medicina existe um alto número de doenças que podem acometer o ser humano. A previsibilidade de 
acontecimento destas doenças bucais é alta, enquanto na medicina a previsibilidade de ocorrência de doenças ainda é baixa. O número de especialidades em cada uma dessas áreas reflete estas características: na odontologia existem 19 especialidades regularmente reconhecidas pelo Conselho Federal de Odontologia ${ }^{23}$ (1.Cirurgia e Traumatologia BucoMaxilo-Facial; 2.Dentística; 3.Disfunção Têmporo-Mandibular e DorOrofacial; 4.Endodontia; 5.Estomatologia; 6.Radiologia Odontológica e Imaginologia; 7.Implantodontia; 8.Odontologia Legal; 9.Odontogeriatria; 10.Odontopediatria; 11.Odontologia do Trabalho; 12.Odontologia para Pacientes com Necessidades Especiais; 13.Ortodontia; 14.Ortopedia Funcional dos Maxilares; 15.Patologia Bucal; 16.Periodontia; 17.Prótese Buco-Maxilo-Facial; 18.Prótese Dentária; 19.Saúde Coletiva), enquanto que pelo Conselho Federal de Medicina existem 56 especialidades $^{22}$ (1.Acupuntura; 2.Alergia e imunologia; 3.Anestesiologia; 4.Angiologia; 5.Cancerologia; 6.Cancerologia/ cancerologia cirúrgica; 7.Cancerologia/ cancerologia clínica; 8.Cancerologia/ cancerologia pediátrica; 9.Cardiologia; 10.Cirurgia cardiovascular; 11.Cirurgia da cabeça e pescoço; 12.Cirurgia do aparelho digestivo; 13.Cirurgia geral; 14.Cirurgia pediátrica; 15.Cirurgia plástica; 16.Cirurgia torácica; 17.Cirurgia vascular; 18.Clinica médica; 19.Coloproctologia; 20.Dermatologia; 21.Diagnóstico por imagem (com atuação exclusiva); 22.Edocrinologia; 23.Endoscopia; 24.Gastroenterologia; 25. Genética médica; 26.Geriatria; 27.Ginecologia e obstetrícia; 28. Hematologia e hemoterapia; 29.Homeopatia; 30.Infectologia; 31.Mastologia; 32.Medicina de família e comunidade; 33.Medicina do 
trabalho; 34.Medicina do trafego; 35.Medicina esportiva; 36.Medicina física e reabilitação; 37.Medicina intensiva; 38.Medicina legal; 39.Medicina nuclear; 40.Medicina preventiva e social; 41.Nefrologia; 42.Neurocirurgia; 43.Neurologia; 44.Nutrologia; 45.Oftalmologia; 46.Ortopedia e traumatologia; 47.Otorrinolaringologia; 48.Patologia; 49.Patologia clinica/medicina laboratorial; 50.Pediatria; 51.Pneumologia; 52.Psiquiatria; 53.Radiologia e diagnóstico por imagem; 54.Radioterapia; 55.Reumatologia; 56.Urologia).

Outra diferença que pode ser observada é que, com exceção de acidentes ou dores de dente, a necessidade de tratamento odontológico raramente pode ser considerada uma emergência e os casos não tratados raramente possuem conseqüências dramáticas na saúde dos indivíduos. Pode-se dizer que, relativamente às doenças médicas, raramente há risco de vida nos casos de doenças bucais. Por conseguinte, os indivíduos podem se planejar livremente em relação a quando realizar um tratamento odontológico, sendo razoavelmente comum o indivíduo adiar suas visitas ao cirurgião dentista, mesmo na presença de doenças bucais. Tal característica possibilita ao indivíduo maior liberdade na escolha do profissional que irá atendê-lo, o que, em tese, é mais um motivo que o torna mais sensível às alterações nos preços dos procedimentos odontológicos. O mesmo não ocorre em relação aos procedimentos médicos, na presença de uma doença, o indivíduo tende a ficar disposto a pagar qualquer quantia para a realização do seu tratamento. ${ }^{6}$

Os tratamentos odontológicos freqüentemente são adiados pelos indivíduos. Cáries e doenças periodontais podem se desenvolver com 
poucos sintomas e pouca ou nenhuma dor. Um dente com uma cárie extensa ou a perda de um dente devido a problemas periodontais não acontecem da noite para o dia. Pode levar meses ou até anos para que estas duas doenças se tornem graves. E, na maioria das vezes, quando os sintomas aparecem, a doença já se encontra em estado grave e, provavelmente, o tratamento requerido será oneroso. ${ }^{6,42,43}$

A presença de demanda no caso de planos odontológicos é potencializada pelo excesso de oferta no mercado de cirurgiões-dentistas, gerado por distorções no mercado educacional e que acentuam a concorrência entre os cirurgiões-dentistas, levando a um resultado pouco eficiente para a classe em geral $^{58}$

O desenvolvimento da odontologia suplementar favorece 0 surgimento de mais uma opção de trabalho assalariado para o cirurgiãodentista, principalmente em períodos de crise no modelo liberal de atuação da profissão e de perda do poder aquisitivo da população. ${ }^{50}$

Entender as relações que ocorrem nessas práticas profissionais possibilita avaliar o dinamismo e as contradições da realidade social na qual os odontólogos estão ou pretendem estarem inseridos. 
2 Revista da Literatura 


\section{ReVISTA DA LITERATURA}

\subsection{SAÚDE SUPLEMENTAR}

No século passado, o sistema de saúde brasileiro apresentou importantes mudanças. As políticas de saúde que são desenvolvidas em cada período de governo influenciam diretamente as práticas profissionais na área de saúde. Para compreender adequadamente o significado da Saúde Suplementar no sistema de saúde brasileiro, é necessário realizar uma análise histórica, contextualizando a sua origem e o seu desenvolvimento.

MENDES $^{37}$ faz uma abordagem dividindo o desenvolvimento do sistema de saúde brasileiro, no século $X X$, em três fases: sanitarismo campanhista, modelo médico assistencial privativista e projeto neoliberal. No início dos anos 90, que foi um período de intensa crise política e econômica, estão presentes, na arena sanitária brasileira, dois projetos alternativos em permanente tensão: o projeto neoliberal, portador de hegemonia evidente, e o projeto da reforma sanitária, considerado contra-hegemônico.

O sanitarismo campanhista vigorou desde o final do século XIX até, aproximadamente, 1965. Nesse período a economia brasileira estava voltada para exportação de produtos agrícolas, principalmente o café. $\mathrm{O}$ sistema público de saúde garantia políticas de saneamento dos espaços nos quais ocorria circulação de mercadorias exportáveis e a erradicação ou controle de doenças que poderiam prejudicar a exportação. ${ }^{51}$

OLIVEIRA e TEIXEIRA ${ }^{43}$ ressaltam que, em diferentes países, o desenvolvimento de grandes companhias foi acompanhado do desejo 
empresarial de manter serviços de assistência médica próprios, independentes tanto das práticas médicas no setor privado quanto do setor estatal. De acordo com esses autores, as principais vantagens da existência de um serviço médico dentro da empresa são: a seleção de pessoal, o controle do absenteísmo da força de trabalho empregada, a possibilidade de obter um mais rápido retorno da força de trabalho à produção e a política de pessoal mais "atraente". No Brasil, esse interesse das empresas surgiu junto com a industrialização. Desde o final do século XIX, algumas companhias maiores estabeleceram, no seu interior, serviços médicos próprios. O Estado liberal da época abstinha-se desse tipo de atividade. Em 1882, a Associação Industrial, organizada no Rio de Janeiro, lançou um manifesto, escrito por Felício dos Santos, considerando que o país só sairia da crise econômica se desenvolvesse a indústria. Após a proclamação da República, no governo de Floriano Peixoto (1891-1894), houve grande incentivo para o desenvolvimento da indústria nacional, que estimulou o surgimento de novas relações de trabalho. A Primeira Guerra Mundial (19141918) também gerou condições para o crescimento do setor fabril brasileiro, promovendo um grande surto industrial.

O crescimento industrial fortaleceu a burguesia industrial, a classe média urbana e o operariado, que passaram a reivindicar melhores condições de vida. As contestações e pressões desses grupos, associadas aos movimentos da Juventude Militar do Exército (Tenentismo) e às dissidências dentro da classe dominante, geraram, no campo político, o 
declínio do poder das oligarquias, principalmente 0 das oligarquias cafeeiras. $^{43}$

MENDES $^{37}$ considera que o processo de industrialização, além de colocar fim ao modelo econômico agro-exportador, estimulou o aparecimento da assistência médica da Previdência Social em 1923. Nessa mesma época, foi criada a primeira Caixa de Aposentadoria e Pensões, a CAP dos Ferroviários. Em 1930 já existiam 47 CAP's que davam cobertura a 142.464 beneficiários. Posteriormente, em 1933, iniciou-se na Previdência social a organização de Institutos de Aposentadorias e Pensões (IAP's), estruturados por categorias profissionais. DONNANGELO ${ }^{30}$ afirma que, nesse período, também foram criados o Conselho Superior de Previdência Social, órgão de recurso em questões relacionadas com prestações e contribuições, e o Departamento de Previdência social, órgão de supervisão e controle geral dos Institutos, ambos do Ministério do Trabalho. Nessa época, OLIVEIRA e TEIXEIRA ${ }^{43}$ observaram que a assistência médica da Previdência Social era prestada, predominantemente, através dos serviços próprios dos Institutos. Ainda não existiam os convênios-empresa, e o setor credenciado, nascido na década de 30, era minoritário. As empresas em geral e os fornecedores privados de serviços de saúde ainda não tinham demonstrado interesse pela política previdenciária de assistência médica.

O processo de industrialização sofre uma considerável aceleração a partir da década de 50 , o que determinou intensas mudanças sociais. A massa operária teve um grande crescimento, o pólo dinâmico da economia foi deslocado para os centros urbanos e o foco do sistema de saúde deixou 
de ser o ambiente de trânsito de mercadorias e passou a ser a saúde do trabalhador, que era "peça" fundamental para o desenvolvimento da economia industrial. O modelo sanitarista campanhista torna-se inadequado perante todas as mudanças que aconteceram.

Em 1960, no governo do presidente Juscelino Kubistchek, é promulgada a Lei Orgânica da Previdência Social ${ }^{12}$, que garantia a uniformização dos benefícios. No período de 1964, amplia-se o poder regulador do Estado, sendo reduzido o poder dos trabalhadores no controle da Previdência Social. Segundo OLIVEIRA e TEIXEIRA ${ }^{43}$ em 1964, a Previdência Social brasileira começa a realizar financiamento da assistência médica das empresas, com um convênio estabelecido entre o IAPI e a Volkswagen no qual a Previdência Social deixava de ter responsabilidade de prestar assistência médica aos empregados da instituição conveniada, que assumia essa responsabilidade. A empresa ficava dispensada de parte da contribuição para a Previdência Social.

De acordo com PIOLA ${ }^{48}$ o convênio não constitui modalidade de contrato. É uma forma de ajuste entre o Poder Público e entidades públicas ou privadas para a realização de objetivos de interesse comum, mediante mútua colaboração, que pode assumir várias formas, como repasse de verbas, uso de equipamentos, de recursos humanos, de materiais, de imóveis, de know- how e outros. No convênio não se estabelece preço ou remuneração. As verbas públicas repassadas continuam sendo dinheiro público, o que obriga a entidade conveniada a prestar contas de sua 
utilização tanto para o ente repassador quanto para o Tribunal de Contas da União.

O convênio está disciplinado pelo art. 116 da Lei n. ${ }^{\circ} 8.666 / 93^{16}$. SZKLAROWSKY ${ }^{57}$ ressalta que no contrato os interesse das partes são divergentes. No convênio, os signatários do documento, denominados partícipes, associam-se para a execução de um objeto. Nessa situação os partícipes possuem interesses convergentes. PIOLA ${ }^{48}$ considera que, geralmente, quando o Poder Público realiza convênio com entidades privadas, é para estabelecer uma cooperação ou para incentivar ou ajudar um particular a prestar determinada atividade. Nesse caso, o convênio serve mais para atividade de fomento, ou seja, atividade administrativa de incentivo à iniciativa privada de utilidade pública.

Os convênios-empresa representaram uma conquista dos empresários, acrescentando-se a isso a ocorrência de um afastamento dos trabalhadores do centro de decisão política da Previdência Social. Em 1966, ocorre a substituição dos IAP's pelo Instituto Nacional da Previdência Social (INPS). Configura-se uma nova fase no sistema de saúde brasileiro: a fase do modelo médico-assistencial privatista. Nessa mesma época, OLIVEIRA e TEIXEIRA $^{43}$ relatam que nasceram a Federação Brasileira de Hospitais (FBH) e a Associação Brasileira de Medicina de Grupo (ABRAMGE).

$\mathrm{BAHIA}^{5}$ considera que os trabalhos sobre o empresariamento da medicina relacionam as mudanças na organização privada dos serviços de saúde às políticas previdenciárias implantadas após a unificação dos Institutos de Aposentadorias e Pensões. A Previdência é transformada no 
maior comprador de serviços médicos do país. A subordinação da produção de atividades assistenciais à lógica da remuneração por produção favorece o desenvolvimento de várias modalidades de privatização da assistência médica. Tanto o produtor privado isolado (hospitais, laboratórios, etc) quanto os grupos médicos que criam empresas para a prestação de serviço a outras empresas apresentam expressivo desenvolvimento nesse período.

MENDES $^{37}$ relata que na década de 70 houve uma ampliação do âmbito de ação da Previdência Social (inclusão dos trabalhadores domésticos, dos autônomos e do trabalhador rural, por exemplo), mas ficava evidente um aspecto discriminatório da política de saúde, considerando as diferenças encontradas no acesso à assistência à saúde garantida pela Previdência Social. A expansão da clientela da Previdência Social favoreceu o desenvolvimento do setor privado, que recebia incentivos do poder público na forma de contratos e credenciamentos, recebendo por serviços prestados, e convênios recebendo subsídio fixo. Em 1974, a implantação do Plano de Pronta Ação, no governo do presidente Ernesto Geisel (1974 1979), favoreceu o crescimento de uma nova modalidade assistencial: a medicina de grupo, viabilizada pelo convênio-empresa. Esse tipo de convênio viabilizou o nascimento e desenvolvimento do subsistema, que seria hegemônico na década de 80: o da Saúde Suplementar. O Plano de Pronta Ação universalizou a atenção às urgências. $M E N D E S^{37}$ afirma que o PPA reorganizou as relações da Previdência Social com diferentes prestadores através de formas de pagamento distintas: contratos e credenciamentos por serviços prestados e convênios por subsídio fixo. 
A base jurídico-legal do sistema de saúde vigente nos anos 70 foi dada pela Lei $6.229^{12}$, que institucionalizou o modelo médico-assistencial privativista, pela Lei $6.439^{13}$, que criou o Sistema Nacional da Previdência Social e pela Constituição Federal de $1967-69^{10}$. Parcelas expressivas da população eram excluídas da assistência à saúde nesse período. A insatisfação de alguns grupos começou a criar os alicerces políticosideológicos da reforma sanitária. BAHIA ${ }^{5}$ considera que por volta de 1975 ocorreu uma ruptura do padrão de financiamento que a Previdência Social concedia às empresas médicas, o que ocasionou uma autonomização da comercialização de planos de saúde.

$\mathrm{MEDICl}^{36}$ relata o surgimento de um setor autônomo em relação ao setor público. Ao redor desse novo setor estava o Instituto Nacional de Assistência Médica e Previdência Social (INAMPS), estatal e universalizante, e o setor privado, liberal e privatista. Esse autor considera que "o modelo de atenção à saúde no Brasil nasceu e se desenvolveu, até os anos 70, nos marcos do "previdencialismo alemão".

FAVARET e OLIVEIRA ${ }^{32}$ consideram que surgiu no Brasil, na década de 80 , um modelo liberal privatista de assistência à saúde que favoreceu o aparecimento do fenômeno da universalização excludente, que acompanhou o processo de implementação do SUS. O atendimento público de saúde era voltado para a população mais carente e resistente aos mecanismos de racionamento.

A década de 80 foi marcada por grandes mudanças políticas. Em 1986, ocorreu a VIII Conferência Nacional de Saúde ${ }^{9}$, evento marcante na 
fixação de bases para o desenvolvimento da Reforma Sanitária. Nessa Reforma, são abordados três aspectos fundamentais: um conceito abrangente de saúde, como direito de cidadania e dever do Estado, e a instituição de um Sistema Único de Saúde (SUS). Em 1987, ocorreu a implantação do Sistema Unificado e Descentralizado de Saúde (SUDS) e a elaboração da Constituição Federal. MENDES $^{37}$ ressalta que o SUDS apresentou alguns problemas: a superestimação do valor político do setor privado contratado; a forte aliança com o setor de alta tecnologia; a excessiva estadualização da desconcentração, que determina uma ação clientelística de municipalização seletiva e a pouca valorização, na prática, da implantação dos distritos sanitários como catalisadores de mudanças no modelo assistencial vigente. A promulgação da Constituição de 1988 foi um momento marcante na definição de metas que possibilitassem mudanças efetivas no modelo de assistência à saúde vigente, que estava funcionando de forma precária.

As mudanças político-sociais continuaram em andamento. Na década de 90, o Brasil teoricamente estava de "roupa nova". A Constituição Federal de $1988^{11}$, as Constituições Estaduais, as Leis Orgânicas municipais, a Lei $8.080^{14}$, de 19 de setembro de 1990 , e a Lei $8.142^{15}$, de 28 de dezembro de 1990 davam base legal para mudanças no sistema de saúde brasileiro. $\mathrm{Na}$ prática, o país estava vivenciando um contexto político neoliberal baseado na privatização, descentralização e na focalização. Na Constituição Federal de $1988^{11}$, a saúde foi considerada um direito de todos e um dever do Estado. Essa Constituição foi promulgada em um período no qual o setor 
público estava totalmente defasado, com exceção do setor de alta tecnologia. Por outro lado, o setor privado estava em amplo desenvolvimento, principalmente aquele considerado suplementar ao setor público. De acordo com a Constituição, a assistência à saúde seria livre à iniciativa privada.

É mencionada, na Carta Magna ${ }^{11}$, a possibilidade de participação de instituições privadas, de forma complementar, no SUS, mediante contrato de direito público ou convênio.

Bem antes de surgir a idéia de um Sistema Único de Saúde, já existiam entidades privadas credenciadas, contratadas ou conveniadas com a Administração Pública. Seria irreal esquematizar um Sistema Único de Saúde no qual fosse permitida a participação apenas do setor público. Existia um sistema de saúde que seria adaptado de acordo com as normas operacionais do SUS. Participar de forma complementar no SUS significa estar integrado ao Sistema, recebendo verbas e atuando de acordo com as suas diretrizes $^{14}$. Na Constituição Federal ${ }^{11}$ é dada preferência às entidades filantrópicas e às sem fins lucrativos para participarem de forma complementar no SUS. O racionamento financeiro que ocorre na área de saúde tem contribuído para um movimento de retirada das melhores entidades privadas que fazem parte do Sistema Único de Saúde. Isso acaba contribuindo para uma queda na qualidade dos serviços do SUS e para uma ampliação dos serviços no setor de Saúde Suplementar. A Saúde Suplementar não recebe verba direta do SUS e possui baixa regulação do 
Estado. A expansão desse setor ocorre em função da perda de qualidade do setor público.

Os trabalhadores, em suas reivindicações, exigem planos de saúde ao invés de melhorias no SUS. É importante ressaltar que nem sempre é necessário reivindicar esse benefício, pois sua ocorrência, em alguns casos, é natural. Algumas entidades privadas que integravam o SUS na forma complementar estão entrando no setor suplementar, para onde existe também um fluxo de pacientes que não se submetem aos serviços oferecidos pelo SUS. A população que freqüenta os serviços públicos de saúde possui baixa atividade reivindicatória, o que não contribui para uma melhoria desses serviços. Paulatinamente, o modelo médico-privatista vai sendo substituído pelo projeto neoliberal de saúde que, no final dos anos 80 , era composto por três subsistemas: o de alta tecnologia, o de atenção médica supletiva e o público ${ }^{51}$.

Paralelamente a esses subsistemas, manteve - se presente um subsistema, de caráter privado e representado pelo mercado de desembolso direto de pessoas, no qual os profissionais trabalham como autônomos ou em sociedade. É importante ressaltar que existe uma conjunção de interesses entre o setor de alta tecnologia e o de saúde suplementar, de forma que o primeiro subsidia o segundo na assistência à saúde que envolve alta tecnologia. O Estado participa no financiamento tanto das instituições públicas quanto das instituições privadas que fazem parte do setor de alta tecnologia. 
Atualmente, a Assistência de Saúde Suplementar corresponde a uma parte significativa do mercado de serviços privados na área de saúde. GOUVEIA, citado por MENDES ${ }^{37}$, considera que esse subsistema se beneficia da "universalização excludente", dando cobertura, em 1989, a 22\% da população total do país. Pode-se considerar que essa porcentagem engloba pessoas com algum tipo de renda e seus respectivos dependentes. Segundo dados da ANS ${ }^{1}$, em agosto de 2004, 37.770.800 indivíduos eram beneficiários de planos de saúde em todo o país, este total representa em torno de $20 \%$ da população brasileira.

ALMEIDA $^{3}$ considera que, na última década, este tipo de assistência apresentou crescimento expressivo, o qual ocorreu paralelamente à implantação do Sistema Único de Saúde. Nesse período, o setor privado passou a ser requisitado para o desempenho de funções que liberassem o Estado das funções assistenciais e até das fiscais. Os conflitos entre os diversos atores que participam da assistência de saúde suplementar também se intensificaram nesta época, acelerando o processo de regulamentação específica. Por um lado, estavam os consumidores que, insatisfeitos com a elevação dos preços e com as restrições de cobertura dos planos de saúde, vinham acionando as entidades de defesa do consumidor, o poder judiciário e os meios de comunicação. A elevação dos preços ocorreu inclusive em períodos de estabilização econômica. Por outro lado, existiam demandas do próprio governo de reformulação do setor de seguros que rebatiam como pontos específicos na agenda de regulamentação dos planos e seguros privados de saúde. 
MONTONE ${ }^{41}$ considera que o setor de Saúde Suplementar operou ao longo de mais de trinta anos fora da esfera de controle do Estado. De acordo com dados do Ministério da $\operatorname{Saúde}^{40}$, uma quinta parte da população brasileira, aproximadamente, está envolvida com esse setor, no qual há uma movimentação financeira anual na faixa de 23 bilhões de reais. Apesar dessas observações, nesse período, o setor de Saúde Suplementar esteve agindo de acordo com sua própria lógica e estabelecendo suas próprias regras, praticamente sem ocorrer qualquer tipo de interferência governamental.

No início dos anos noventa, houve as primeiras tentativas de regulamentação desse setor, contudo o setor de Saúde Suplementar passou a integrar a agenda da sociedade e do governo apenas em $1997^{17}$. O resultando foi a regulamentação ocorrida em junho de $1998^{19}$, processo intensificado após a efetiva implantação da Agência Nacional de Saúde Suplementar (ANS) em abril do ano $2000^{18}$.

MONTONE ${ }^{41}$ analisou o perfil do usuário do setor de Saúde Suplementar, utilizando dados da Pesquisa Nacional por Amostra de Domicílios (PNAD) de $1998^{35}$, realizada pelo IBGE. Nesse ano, estimou-se que 38,7 milhões de brasileiros eram beneficiários de planos privados de assistência à saúde, sendo a distribuição geográfica dessa população extremamente concentrada na zona urbana (95\%). Em relação à distribuição da população por faixa de rendimentos, $52 \%$ dos beneficiários do setor de Saúde Suplementar possuem renda média familiar inferior a 10 saláriosmínimos. A população feminina usuária de plano privado de assistência à 
saúde é majoritária (54\%) e a parcela da população com menos de 40 anos representa $2 / 3$ do total de usuários (67\%) desses planos.

A primeira etapa do processo de regulamentação foi caracterizada pela fixação do marco legal. As publicações da Lei $9.656^{17}$, em 4 de junho de 1998 , e da MP $1.665^{19}$, em 5 de junho de 1998, iniciaram o processo de regulamentação do setor de Saúde Suplementar, após vários anos de debate no Congresso Nacional.

Nessa primeira fase ficou estabelecido que o Ministério da Fazenda, representado pelo Conselho Nacional de Seguros Privados (CNSP) e pela Superintendência de Seguros Privados (SUSEP), seria responsável por aspectos econômico-financeiros relacionados com as operadoras. $\mathrm{O}$ Ministério da Saúde, representado pelo Conselho Nacional de Saúde suplementar (CONSU) e pela Secretaria de Assistência à Saúde (SAS) I Departamento de Saúde Suplementar (DESAS) assumiu a responsabilidade em supervisionar o produto oferecido como um tipo de assistência à saúde.

De acordo com o artigo $6 .^{\circ}$ da Resolução $N .^{\circ}$ XX/98 do $\mathrm{CNSP}^{40}$, que regulamenta as operadoras de seguros ou planos privados de assistência à saúde, e dá outras providências, as operadoras do mercado privado de assistência à saúde são classificadas nas seguintes modalidades:

A. Operadoras de seguros de saúde: são exclusivamente as seguradoras, constituídas conforme legislação específica para a atividade de seguros, e que oferecem obrigatoriamente o reembolso das despesas médicohospitalares e/ou odontológicas em todos os seus planos do ramo saúde; 
B. Operadora de planos de saúde: são empresas, constituídas sob quaisquer formas jurídicas, que comercializam planos de assistência à saúde, atuando nessa atividade, podendo fornecer adicionalmente prestação de serviços médico-hospitalares e/ou odontológicos diretos ou indiretos;

C. Operadoras de planos odontológicos: são empresas constituídas sob quaisquer formas jurídicas que comercializam planos odontológicos, atuando exclusivamente nessa atividade, podendo fornecer a prestação direta ou indireta de serviços odontológicos;

D. Operadora de autogestão principal: são empresas que atuam em quaisquer atividades, que oferecem planos de assistência à saúde exclusivamente a seus funcionários ativos, aposentados, pensionistas, exempregados, seus respectivos grupos familiares, limitados ao terceiro grau de parentesco consangüíneo ou afim, ou ainda associações nas quais os seus associados são vinculados a um mesmo empregador, que oferecem planos de assistência à saúde a seus participantes e dependentes;

E. Operadoras de autogestão derivada: são as entidades de classes, sindicatos ou associações, não abrangidas no item "D", que oferecem planos de assistência à saúde a seus participantes e dependentes;

F. Empresas administradoras de planos de saúde: são operadoras que administram planos de assistência à saúde, financiados por quaisquer empresas, sem assumir os riscos dos sinistros.

De acordo com MONTONE ${ }^{41}$, a segunda etapa do processo de regulação ocorreu em setembro de 1999 e apresentou dois movimentos importantes: 
$\checkmark$ A introdução do conceito legal de Plano Privado de Assistência à Saúde para enfrentar a discussão de inconstitucionalidade da inclusão das seguradoras no universo de regulação. O setor de seguros era submetido à legislação específica, o que gerou o questionamento se havia legalidade na inclusão desse setor na esfera de abrangência da regulação. A abrangência da regulação foi dada pelo tipo de produto e não pelas características das empresas ou das entidades que o oferecem. Isso acarretou várias mudanças na legislação, inclusive quanto à exigência de que as seguradoras se reorganizassem como operadoras de planos de saúde para que pudessem continuar atuando no setor.

$\checkmark$ A definição do Ministério da Saúde, representado pelo Conselho de Saúde Suplementar (CONSU) e pela Secretaria de Assistência à Saúde (SAS) / Departamento de Saúde Suplementar (DESAS), como único responsável pelos dois níveis da regulação do setor de saúde suplementar: o econômico-financeiro e o de assistência à saúde.

A terceira etapa do processo de regulação foi a criação da Agência Nacional de Saúde Suplementar, viabilizada pela Medida Provisória $1.928^{20}$ de 25 de novembro de 1999, que em 28 de janeiro de 2000 foi convertida na Lei $9.961^{18}$. Essa Agência assumiu as atribuições da SAS/DESAS quanto ao setor de saúde suplementar. A Câmara de Saúde Suplementar ficou vinculada a esse novo órgão do Ministério da Saúde. A existência de uma agência reguladora no setor de saúde suplementar é de grande importância para a organização desse setor. Em janeiro de 2005, existiam oito agências reguladoras: ADA - Agência de Desenvolvimento da Amazônia, ANA - 
Agência Nacional de Águas, ANEEL - Agência Nacional de Energia Elétrica, ANATEL - Agência Nacional de Telecomunicações, ANTT - Agência Nacional de Transportes Terrestres, ANP - Agência Nacional de Petróleo, ANS - Agência Nacional de Saúde Suplementar, e ANVISA - Agência Nacional de Vigilância Sanitária.

MONTONE ${ }^{41}$ destaca três aspectos importantes das agências reguladoras:

- Poder regulador definido em lei;

- A autonomia administrativa;

- A autonomia financeira.

Em 3 de junho de 1998 foi aprovada a Lei $9.656^{17}$, que dispõe sobre os planos e seguros privados de assistência à saúde. A Medida Provisória $1.928^{20}$, de 25 de novembro de 1999 criou a Agência Nacional de Saúde Suplementar, que tem como finalidade institucional promover a defesa do interesse público na assistência suplementar à saúde, regulando as operadoras setoriais, inclusive quanto às suas relações com prestadores e consumidores. PIOLA et al. ${ }^{48}$, estudando o Sistema de Saúde Brasileiro, consideram que a quantidade de pessoas vinculadas a planos e seguros de saúde deverá aumentar nesta década, que os usuários ficarão satisfeitos com as medidas de regulação do setor de planos e seguros de saúde e que a Agência Nacional de Saúde Suplementar (ANS), como órgão regulador, terá boa atuação como fiscalizadora de operadoras, controladora de preços, mas não impedirá o predomínio das grandes empresas de assistência médica suplementar sobre as de menor porte. 
De acordo com a RDC n. ${ }^{\circ} 39^{38}$, de 27 de outubro de 2000 da ANS, as operadoras de planos de saúde são classificadas da seguinte forma:

A. Administradoras: empresas que administram planos ou serviços de assistência à saúde. Quando administram planos, são financiadas pela operadora, não assumem o risco decorrente da operação dos planos e não possuem rede própria, credenciada ou referenciada de serviços médicohospitalares ou odontológicos;

B. Cooperativa Médica: Cooperativa que opera Planos Privados de Assistência à Saúde;

C. Cooperativa Odontológica: Cooperativa que opera, exclusivamente, Planos Odontológicos;

D. Autogestão: é a modalidade na qual órgãos públicos, entidades da Administração Pública Indireta e empresas privadas operam serviços de assistência à saúde ou que, por intermédio de seu departamento de recursos humanos ou órgão assemelhado, responsabilizam-se pelo Plano Privado de Assistência à Saúde, destinado, exclusivamente, a oferecer cobertura aos empregados ativos, aposentados, pensionistas ou exempregados bem como a seus respectivos grupos familiares definidos, desde que estejam dentro do limite do terceiro grau de parentesco consangüíneo ou afim, de uma ou mais empresas, ou ainda a pessoas, com seus respectivos dependentes, vinculadas a associações de pessoas físicas ou jurídicas, fundações, sindicatos, entidades de classes profissionais ou assemelhados; 
E. Medicina de Grupo: São classificadas nessa modalidade as empresas ou entidades que operam Planos de Privados de Assistência à Saúde, excetuando-se as Administradoras, as Cooperativas Médicas, as Autogestões e as Entidades Filantrópicas. ALMEIDA ${ }^{3}$ define Medicina de Grupo como sendo empresas médicas que administram planos de saúde para órgãos públicos entidades, empresas privadas, indivíduos ou famílias, e trabalham com vários tipos de planos. A estrutura de atendimento é esquematizada em serviços próprios e/ou credenciados. O acesso à rede própria ou credenciada é livre e, nos planos mais caros, é previsto o uso de serviços não credenciados, sendo concedido ressarcimento dos gastos, baseado em valores da tabela da Associação Médica Brasileira (AMB) e da Associação Brasileira de Hospitais (ABH), o que não garante reposição total das despesas realizadas pelo usuário do plano de saúde;

F. Odontologia de Grupo: são empresas que administram, exclusivamente, Planos Odontológicos para órgãos públicos, entidades, empresas privadas, indivíduos e famílias. A estrutura de atendimento é esquematizada em serviços próprios e/ou credenciados;

G. Filantropia: são entidades sem fins lucrativos que operam Planos Privados de Assistência à Saúde e que tenham obtido certificado de Entidade Filantrópica fornecida pelo Conselho Nacional de Assistência Social (CNAS) e declaração de utilidade pública federal fornecida pelo Ministério da Justiça ou declaração de utilidade pública estadual ou municipal junto Órgãos dos governos Estaduais e Municipais. Na prática, entretanto, observa - se que as entidades filantrópicas operam em parceria 
com seguradoras, seguindo a mesma lógica das operadoras com fins lucrativos.

Atualmente, de acordo com a Lei $9.656^{17}$, as seguradoras também são classificadas como um tipo de operadora. A RDC n. ${ }^{\circ} 65^{39}$, de 24 de abril de 2001, aborda alguns aspectos das Sociedades Seguradoras especializadas em saúde.

\subsection{A PRÁTICA OdONTOLÓGICA}

Existem relatos históricos de que inicialmente a odontologia era exercida por diferentes tipos de profissionais. Os primeiros terapeutas dentais foram médicos, sendo que na idade média os "cirurgiões-barbeiros" europeus se especializaram no tratamento dos dentes. ${ }^{49}$

Antigamente, a prática odontológica era extremamente empírica. Com o passar do tempo, alguns profissionais foram se especializando no tratamento de problemas relacionados com a cavidade oral. Começou, então, a surgir uma nova área de conhecimento. No século XVIII, o francês Pierre Fouchard, por meio de seu grande tratado Le Cirurgian Dentiste, estabeleceu princípios científicos que caracterizaram a Odontologia como uma verdadeira profissão ${ }^{49}$

A tecnologia e a ciência aplicadas à Odontologia possibilitaram o desenvolvimento de inúmeras possibilidades de tratamento, mas a estrutura do atendimento odontológico foi ficando com o custo cada vez mais elevado. As variadas técnicas desenvolvidas exigem materiais, instrumentais e 
equipamentos adequados para a sua realização. Dessa forma, o tratamento foi ficando cada vez mais caro e restrito a uma parcela da população que possuía condições financeiras suficientes para gastos com serviços odontológicos. O cirurgião-dentista, que no passado vivenciou, inclusive, a experiência como ambulante, fixou-se em um determinado ponto comercial para estruturar o seu consultório que, diferentemente do consultório médico, exigia especial estrutura, pois o atendimento odontológico, desde aquela época, já envolvia procedimentos individuais de intervenção na boca dos pacientes. ${ }^{49,58}$

Em odontologia, alguns fatores normalmente são levados em consideração no momento da opção pela carreira. No Brasil, até uns 15 ou 20 anos atrás, ser cirurgião-dentista era quase sinônimo de alta renda. Portanto, vários jovens de classes mais baixas eram atraídos pela possibilidade de enriquecimento com o exercício da profissão. Até hoje existe a ilusão de que ser cirurgião-dentista é sinônimo de sucesso financeiro e essa impressão é, de certa forma, sustentada pelos professores nos cursos de odontologia, de atualização e de especialização, pois aqueles que dão aula nesses cursos são exatamente a elite da classe de odontólogos, aqueles que tiveram sucesso na profissão e isso sugere aos alunos que a profissão odontológica ainda é altamente rentável. ${ }^{58}$

Outro fator que também influencia a decisão de se tornar dentista é a vontade dos pais, quando estes são cirurgiões-dentistas, influenciando a decisão de seus filhos, haja vista a possibilidade de "herdar" os pacientes dos pais. Em alguns casos, o verdadeiro desejo do indivíduo é ser médico. 
No entanto, após algumas tentativas frustadas de ingressar em um curso de medicina, este resolve optar pela sua segunda opção, ou seu second best, que muitas vezes é o curso de odontologia. ${ }^{58}$

PEREIRA $^{45}$ afirma que no senso comum, existe uma visão mítica de que a educação formal constitui um canal de ascensão social e econômica por excelência. Acredita-se que quem passar pelos graus mais adiantados do ensino obterá vantagem na disputa por posições sociais mais privilegiadas. E a odontologia, como uma das últimas profissões liberais, vinha alimentando o sonho de ascensão de muitos indivíduos. E desde que a proporção de diplomados se torne elevada, dadas as facilidades para a obtenção desses títulos, a tendência será de queda do prestígio, da remuneração e do mérito atribuído ao diploma.

Segundo $\mathrm{PINTO}^{47}$ quando alguém se forma e não encontra o que fazer tem um problema pessoal, que repercute apenas entre seus amigos e na sua família. Mas quando não apenas uma pessoa nem uma dúzia, mas turmas inteiras de profissionais se vêem com reduzidas perspectivas de trabalho ao concluir o curso, a questão torna-se um problema de massa. Torna-se cada vez mais comum a constatação, pelo profissional, de que é possível ser uma pessoa diplomada e desempregada, ou sem perspectivas para atuação dentro dos preceitos de sua formação.

Cabe ressaltar que os requisitos para um portador de diploma de graduação em Odontologia exercer legalmente a profissão no país são apenas o pagamento da taxa de inscrição do Conselho Regional de Odontologia (CRO) do estado no qual pretende exercer suas atividades e, 
por conseguinte, o pagamento da anuidade. Ou seja, não há barreira à entrada em relação à qualidade, basta concluir o curso de graduação. ${ }^{23}$

De acordo com CORDÓN ${ }^{27}$, quando a prática odontológica surgiu foi desenvolvida em clínicas privadas, onde os profissionais, trabalhando de uma forma artesanal, detinham os meios de produção e possuíam liberdade para estabelecer o esquema de trabalho, selecionar os pacientes e determinar o valor dos seus respectivos honorários. Posteriormente, iniciouse uma progressiva intervenção do Estado nas profissões liberais. Surgiram normas que restringiram a atuação do profissional liberal. A prática odontológica tem sofrido inúmeras alterações desde os tempos remotos. Essas modificações, geralmente, estão relacionadas tanto com o desenvolvimento científico e tecnológico da profissão como com a forma de acesso ao tratamento odontológico. Essas mudanças não ocorrem de forma isolada na sociedade. Estão intimamente relacionadas com o dinamismo da realidade sócio - econômica do país. Considerando que a saúde está se transformando em um bem de consumo, qualquer alteração na política econômica afeta indiretamente a área de saúde. A alteração do poder aquisitivo de uma pessoa faz com que ela inclua ou exclua gastos. $\mathrm{O}$ tratamento odontológico parece ser, geralmente, excluído dos gastos quando ocorre queda de poder aquisitivo da população, situação observada em períodos de crise econômica.

A Odontologia no Brasil é uma assistência predominantemente privada, curativa e socialmente excludente, onde a maior parte do tempo e do dinheiro gastos com saúde bucal são pertencentes ao setor privado e a 
grande massa da população tem acesso limitado ou nenhum a este sistema de atenção odontológica. Segundo Pesquisa Nacional por Amostra de Domicílios $(P N A D)^{35}$, realizada pelo IBGE, cerca de 29 milhões de brasileiros nunca receberam nenhum tipo de assistência odontológica.

A cobertura e a abrangência da assistência bucal oferecidas pelo setor público ainda são incipientes. No entanto, o Estado possuiu um papel relevante na melhoria dos índices de saúde bucal brasileiros a partir da fluoretação das águas distribuídas à população e da inserção do flúor nas pastas de dente.

Melhorar os índices de saúde bucal significa, na prática, que cada vez mais as pessoas têm mantido seus dentes na boca, isto é, a quantidade de dentes perdidos tem diminuído. Seguindo este raciocínio, quanto mais as pessoas mantêm seus dentes, mais dentes ficam expostos a doenças bucais. Ou seja, mais e mais pessoas necessitam de atenção odontológica. O mesmo raciocínio pode ser feito em relação ao envelhecimento da população. Antigamente, as pessoas mais idosas geralmente eram edentadas, isto é, não possuíam mais nenhum dente na boca, ou em alguns casos, poucos dentes. Com a maior exposição da população ao flúor, dentre outros fatores, os idosos estão retendo mais dentes na boca. Enfim, a partir deste raciocínio pode-se imaginar que a demanda por assistência odontológica tende a aumentar cada vez mais, em função de mudanças no perfil populacional. Outro dado importante é a necessidade de crescimento do nível de renda da população, a fim de impulsionar o crescimento do mercado de odontologia como um todo. 
A prática odontológica no Brasil desenvolveu-se como sendo uma atividade paralela aos serviços médicos, tanto no setor público quanto no privado. Enquanto a medicina entrou em um processo de socialização, principalmente com o desenvolvimento do conceito de saúde como direito, a odontologia se manteve durante muitos anos no setor privado, sendo exercida predominantemente como uma atividade autônoma. CORDÓN ${ }^{25}$ ressalta que o trabalho odontológico atual é fortemente dependente dos avanços tecnológicos da sociedade. Os equipamentos, materiais, medicamentos e instrumentais usados na prática odontológica apresentam níveis crescentes de sofisticação, o que eleva os custos do trabalho odontológico e dificulta a sua expansão.

Segundo o $\mathrm{CFO}^{23}$, o número de profissionais ingressando anualmente no mercado odontológico gira em torno de 12.000 cirurgiões-dentistas por ano. Os motivos que levam um indivíduo a resolver entrar para a carreira de odontologia, vão desde o desejo dos pais, quando estes também são odontólogos, o reconhecimento e o status que o título de cirurgião-dentista pode proporcionar, a idéia (e porque não dizer a ilusão) de que esta profissão é sinônima de altos salários, o fato de ser uma profissão predominantemente autônoma, o que atrai os indivíduos pela possibilidade de poder fazer opções em relação à quantidade de horas trabalhadas, e por aí vai. Entretanto, o mercado hoje não oferece condições de trabalho em consultório particular para toda a gama de profissionais. Em parte devido à escassez de recursos da população, em parte devido a aspectos culturais. Muitos optam por diferentes formas de prestação de serviço, porém, outros 
simplesmente decidem tentar novas profissões e pedem o cancelamento de seus registros. Outros fatores que levam ao cancelamento de registros são a aposentadoria, a morte ou a mudança de estado dos profissionais.

A relação entre a população e o número de cirurgiões-dentistas normalmente é calculada dividindo-se o número total da população pelo número total de cirurgiões-dentistas inscritos no Conselho Federal de Odontologia. Desta forma, pode-se saber quantos pacientes potenciais existem para cada profissional. A Organização Mundial de Saúde (OMS) recomenda a relação de um dentista para cada 1.500 pessoas como uma relação adequada. Um número de pessoas muito acima desse sugere uma escassez de profissionais, e um número de pessoas muito abaixo sugere um excesso de profissionais. No Brasil a relação gira em torno de um cirurgiãodentista para cada 945 pessoas. ${ }^{23}$

ZANETTI $^{58}$ ressalta que nas décadas de 80 e 90 a Odontologia Brasileira passa a conviver intimamente com mudanças sócio-econômicas e com uma evolução técnico-científica na área odontológica. O grande número de pessoas necessitadas de tratamentos odontológicos induziu a abertura de Faculdades de Odontologia de uma forma desordenada que fez o Brasil receber os títulos de campeão em número de Faculdades de Odontologia e, paradoxalmente, em número de pessoas com problemas odontológicos.

O Brasil é o País que possui maior número de cursos de odontologia, o maior número de cirurgiões-dentistas graduados por ano e apenas 945 pessoas para serem atendidas por dentista ${ }^{23}$. O lógico seria pensar que, existindo oferta de profissionais mais que suficiente para atender toda a 
população, o nível de saúde bucal deveria ser excelente. No entanto, o índice epidemiológico de saúde bucal é $3,1^{23}$, ficando acima do índice em países nos quais a relação população/dentista é maior. Isso pode ser explicado pela forma como a odontologia é ofertada no país, isto é, atendendo apenas uma pequena parcela da população, ficando o restante da população por conta do setor privado, que é o grande prestador no Brasil. Entretanto, o tratamento odontológico pode possuir um alto custo e apenas uma pequena parcela da população pode acessar esse tipo de serviço.

$\mathrm{Na}$ década de 80 , a prática odontológica começou a sofrer as principais alterações que caracterizariam o novo perfil da profissão nos anos seguintes: crescimento do número de especialistas, surgimento de intermediários na negociação entre profissional e paciente, a proliferação de "Clínicas Odontológicas" e de cirurgiões - dentistas consultores e o desenvolvimento do conceito de saúde bucal coletiva.

CORDÓN ${ }^{26}$ falando sobre a construção histórica do conceito de Odontologia em Saúde Coletiva, comenta sobre os momentos de ruptura epistemológica pelos quais a prática odontológica passou. A primeira ruptura foi quando houve a formação da primeira Faculdade de Odontologia, em Baltimore, em 1840. Nesse momento, a Odontologia sai do âmbito popular e começa a crescer para si mesma. Esse movimento faz com que ocorra uma exclusão na relação social dos cirurgiões-dentistas, sendo desenvolvida uma prática odontológica orientada para os que tinham condições de pagar por uma assistência odontológica caracterizada, principalmente, por procedimentos curativos. A segunda ruptura ocorreu, no século $X X$, nas 
décadas de 40 e 50, quando surgiu uma visão funcional da Odontologia em Saúde Pública. A existência de uma grande quantidade de pessoas com problemas odontológicos começou a preocupar profissionais da área de saúde, principalmente os da área odontológica, fazendo com que surgisse uma filosofia preventiva associada ao uso do flúor, a nível sistêmico e tópico, graças ao Serviço Especial de Saúde Pública (SESP), mais tarde (1960) transformado na Fundação SESP e que recentemente, em decorrência da fusão com a Superintendência de Campanhas de Saúde Pública (SUCAM) gerou a Fundação Nacional de Saúde (FUNASA). A prevenção, viabilizada pelo emprego do flúor, obteve excelentes resultados, pois o $\mathrm{CPO}^{2}$ apresentou grande redução após o emprego do flúor em saúde pública. A terceira ruptura ocorreu na década de 60 , quando ocorre o surgimento da desmonopolização do conhecimento, a simplificação dos procedimentos e a inclusão da prevenção na prática odontológica. A prática odontológica passa a ter um significado social, na medida em que é desenvolvida visando ampliar o acesso das pessoas ao atendimento odontológico.No início da década de 70, foi criado o primeiro curso de especialização em Saúde Pública para cirurgiões - dentistas na Faculdade de Saúde Pública da Universidade Federal de São Paulo (USP). Surge, nesse período, uma filosofia empresarial na prática Odontológica. Paralelamente ocorre o

\footnotetext{
${ }^{2}$ Índice de Ataque de Cárie originalmente formulado por Klein e Palmer em 1937, conhecido pelas iniciais CPO que significa Cariados, Perdidos e Obturados. Ainda que a denominação mais correta, neste último caso, seja 'Restaurado', para efeitos do índice se mantém a inicial "O" como uma concessão à sua melhor eufonia.
} 
desenvolvimento da utilização de pessoal auxiliar em Odontologia. A quarta ruptura representa o momento atual, que está relacionado com o desenvolvimento da Saúde Bucal Coletiva. Esse tipo de prática é caracterizado pela universalidade, eqüidade e integralidade de atenção em Saúde Bucal. Esse é um momento em que a Saúde Bucal passa a ser considerada um direito constitucional e, como tal, deve ser promovida para todos os cidadãos, de acordo com as suas necessidades específicas.

Uma característica muito interessante do Brasil é a quantidade de cirurgiões-dentistas que existem no mercado. Hoje, são mais de 190 mil cirurgiões-dentistas, mais profissionais que o Canadá e os Estados Unidos juntos. No entanto, o índice de saúde bucal não é melhor que o desses países $^{23}$. Apesar desses 29 milhões de brasileiros que nunca foram a um cirurgião-dentista $^{34}$, estes têm reclamado sobre a ociosidade de seus consultórios, que não há mais pacientes. Segundo dados do $\operatorname{IBGE}^{34,35}$, a classe de renda que mais consome serviços odontológicos é a classe com renda superior a nove salários mínimos. Entretanto, esta é a classe onde se encontra cerca de apenas 5\% da população. É neste contexto que entra em cena as operadoras de planos odontológicos, pois são capazes de viabilizar o acesso dos consumidores aos serviços odontológicos, essencialmente mediante os contratos coletivos.

Para SÓRIA et al. ${ }^{56}$ : “... O setor odontológico está atravessando uma fase paradoxal, caracterizada pelo excesso de profissionais no mercado e pelo grande contingente populacional carente de tratamentos odontológicos. 
Os cirurgiões - dentistas são formados para atuarem, predominantemente, em consultório particular, trabalhando individualmente, ou no máximo, com uma auxiliar de consultório dentário. Nos últimos anos observa-se que está crescendo a prática odontológica com intermediários.

Em muitos casos, o fluxo de pacientes dos consultórios é mantido, exclusivamente, pelos chamados "Convênios". Essa situação demonstra a ocorrência de uma inversão, pois, em épocas anteriores, predominava, nos consultórios odontológicos, o fluxo de pacientes particulares, que pagavam diretamente pelos serviços prestados.

A despeito de contar com uma força de trabalho da ordem de 192.122 cirurgiões - dentistas ${ }^{23}$, sem contar os demais profissionais que integram a categoria odontológica, no Brasil os problemas básicos de saúde bucal continuam. Isso ocorre, principalmente, porque à medida que aumenta o número de cirurgiões - dentistas, também aumenta o número de pessoas que não possuem condições financeiras para realizar tratamento odontológico. Por outro lado, alguns problemas de saúde bucal passaram a ser considerados de ordem pública. A implantação da assistência odontológica nos serviços públicos trouxe a esperança de ter acesso ao tratamento odontológico para uma grande parcela da população que está às margens da oferta de serviços odontológicos no setor privado.

O sistema capitalista impõe a existência de "mercados" diversos. Quando a oferta de serviços é elevada, o preço desses serviços tende a cair, fato reforçado pela queda na procura pelos serviços, que também induz a uma queda de preços desses serviços. Desta forma, surgiu a seguinte 
situação contraditória: muitos cirurgiões - dentista com número reduzido de "clientes" e uma grande massa de "pacientes" sem nenhum tipo de assistência odontológica. É como se os cirurgiões-dentistas estivessem de um lado e os pacientes carentes de serviços odontológicos estivessem de outro. O complicador é que não existe nenhum elo que liga os dois lados.

Dentro deste contexto, começaram a surgir "pontes" que tentavam obter algum tipo de vantagem nessa situação, mas sem tentar resolvê-la de forma realista, em sintonia com os problemas sociais do Brasil. BAHIA ${ }^{5}$ ressalta que as reformas setoriais iniciadas na década de 80 , que objetivavam acesso universal, integralidade da atenção, ênfase em ações de proteção e promoção de saúde, descentralização e participação social, adquiriram expressão legal e institucional com a promulgação da Constituição Federal de $1988^{11}$ e com a criação do Sistema Único de Saúde $^{14}$ em 1990. A ponte que uniria aquelas margens começou a ser construída sustentada por estes dois pilares, mas enquanto isso variados tipos de embarcações surgiram para levar pessoas de um lado para o outro, inclusive embarcações que utilizavam aqueles pilares para completar as suas viagens. Estas embarcações visavam lucro ou algum benefício que seria traduzido em algum tipo de ganho material. Estas embarcações são entidades, públicas ou privadas, que começaram a atuar como intermediários na relação profissional paciente, impondo condições para os cirurgiões - dentistas em troca de possibilitar um fluxo de pacientes.

Começaram a surgir, na prática odontológica, empresas que vendem planos de assistência odontológica. O profissional credencia-se na 
esperança de aumentar o fluxo de pacientes e o paciente compra o plano na esperança de obter uma assistência odontológica satisfatória a baixo custo. Pode - se considerar que o excesso de profissionais na área odontológica favorece o desenvolvimento desses esquemas que têm desvalorizado a prática profissional.

ZANETTI $^{58}$ considera que os próprios profissionais começaram a explorar e se apropriar da força de trabalho dos colegas. Profissionais com melhores condições financeiras começam a formar clínicas e a contratar os serviços de colegas pagando um salário fixo e/ou estabelecendo uma relação de arrendamento, na qual o profissional ganha de acordo com a sua produção. Neste último caso, o dono da clínica, ou seja, o empregador não possui nenhum ônus fiscal em relação ao colega que ganha uma porcentagem dos honorários correspondentes à sua produção. O elevado custo de um consultório e a incerteza de ter pacientes faz com que muitos cirurgiões - dentistas, em início de carreira, escolham este último esquema de trabalho. Muitos profissionais especialistas também trabalham dessa forma, em consultórios de colegas, recebendo de acordo com sua produção. Trabalhar nesse esquema pode funcionar como propaganda indireta para uma futura atuação em consultório próprio. Este esquema pode compensar financeiramente, desde que o profissional ofereça apenas a sua força de trabalho, não se responsabilizando pela estrutura desse tipo de prática odontológica.

A prática odontológica puramente autônoma está em processo de transformação. Observa - se uma corrente de mudanças no setor público e 
outra no setor privado. No setor público, há uma tendência de ampliação dos serviços odontológicos, principalmente na área preventiva. No setor privado, existe uma tendência de crescimento dos serviços intermediados por entidades públicas ou privadas. O grande fator que contribui e estimula o desenvolvimento dessas duas correntes é o baixo poder aquisitivo da população e a falta de consciência de que saúde bucal é saúde, e, de acordo com o artigo 196 da Constituição Federal de $1988^{11}$, é direito de todos e dever do Estado.

Ocorreu grande redução no poder aquisitivo da população e, paralelamente, a criação de inúmeras faculdades de odontologia, sem nenhuma avaliação da real necessidade de cirurgiões - dentistas nas diversas Regiões do Brasil. Provavelmente, os profissionais formados nessa época sejam os mais afetados com o crescimento do setor de Saúde Suplementar. ${ }^{2,6}$

O crescimento do setor de saúde suplementar afeta a prática odontológica em aspectos mais burocráticos do que em sua estrutura profissional. Amplia - se o acesso aos trabalhadores, mas ocorre uma queda no valor dos tratamentos. Considerando que não existe adequada assistência odontológica no setor público, a odontologia suplementar está se transformando em uma boa opção para parte da população que deseja realizar tratamentos, mas não possui condições de pagar diretamente um cirurgião - dentista pelos serviços prestados. As principais alterações em decorrência do crescimento do setor de saúde suplementar ocorrem nos processos da prática, onde o intermediário determina o preço e a forma de 
pagamento dos tratamentos odontológicos. A estrutura, os produtos e os resultados não demonstram alterações significativas em decorrência do crescimento do setor de saúde suplementar. Os intermediários foram conquistando espaço na área odontológica. Atualmente, é mais comum o profissional trabalhar com os intermediários do que sem eles. ${ }^{2,6,58}$

A prática odontológica do profissional autônomo é afetada pelo crescimento do setor de Saúde Suplementar, principalmente, em seus processos, ou seja, nos diversos tipos de relações humanas desenvolvidas dentro da estrutura que dá suporte ao atendimento odontológico. A relação profissional - paciente sofre grande interferência do intermediário. Em geral, existe um descontentamento, por parte dos cirurgiões - dentistas, com os valores de preços das tabelas utilizadas pelas operadoras. A burocracia no processo, utilizando peritos e tendo como conseqüência uma demora no pagamento pelos serviços odontológicos prestados, bem como as mudanças na documentação, em função das exigências das operadoras e para pagar menos impostos, são os principais fatores que desgastam os processos da prática odontológica do profissional autônomo. Por outro lado, parece que aumentar rendimentos, ter um fluxo de pacientes maior e garantido, ter garantia de pagamento e realizar uma propaganda indireta do consultório parecem ser as supostas vantagens que fazem com que, atualmente, inúmeros profissionais utilizem os intermediários. Parece que existe mais uma necessidade do que satisfação em trabalhar com as operadoras. 4, 8, 21

Para trabalhar no setor privado como autônomo o cirurgião - dentista tem que ter capital inicial para investir na montagem do seu consultório ou 
Clínica. Os primeiros pacientes, geralmente, são pessoas conhecidas (familiares e amigos), que podem fazer uma propaganda indireta do profissional. Quando o mercado de trabalho é favorável, ou seja, quando não existem tantos profissionais para dar cobertura a uma determinada área, o cirurgião - dentista, progressivamente, vai ficando conhecido pelo seu trabalho e se estabelecendo definitivamente no mercado. A grande maioria dos cirurgiões - dentistas é formada para atuar no mercado de trabalho como autônomo. Acontece, entretanto, que nos grandes centros urbanos existe uma concentração de profissionais que precisam trabalhar para garantir sua sobrevivência. Quando aquele profissional autônomo sai da fase do atendimento de conhecidos, ele fica em um espaço vazio se não conseguir alguma via que canalize pacientes para o seu estabelecimento. Às vezes, esse problema é resolvido por um colega mais antigo que encaminha pacientes para ele. Na prática odontológica, nem sempre existe esse companheirismo entre colegas. Essa situação ocorre, geralmente, quando existe algum grau de parentesco entre os profissionais. Nesse contexto, é comum o cirurgião - dentista entrar no esquema dos intermediários, perdendo sua autonomia, mas garantindo um fluxo de pacientes. ${ }^{2,25,58}$

O profissional autônomo plenamente estabelecido no mercado de trabalho não tem necessidade de muitos atendimentos para ganhar o suficiente para garantir a sua qualidade de vida. O cirurgião - dentista que trabalha com intermediários teria que atender mais pacientes, considerando que as tabelas de preço usadas são muito defasadas. Esse fato faz concluir que trabalhar com intermediários aumenta o faturamento em função de uma 
não ocorrência do paciente particular convencional. A maioria dos pacientes particulares que têm capacidade aquisitiva ou formas de pagamento pelos serviços odontológicos passaram a ser usuários de algum tipo de plano de assistência odontológica, ampliando o seu acesso à saúde bucal. Além disso, alguns setores da população que não possuem esse benefício como salário indireto passaram a recorrer aos intermediários para resolver os respectivos problemas de assistência odontológica. 4, 6, 25

Quando se definiu o setor de Saúde Suplementar e posteriormente a odontologia suplementar, levou - se em consideração que o setor de referência é o público. A movimentação para o setor de Saúde Suplementar ocorre por duas vias: pacientes particulares que passaram a não ter condições de financiar seus tratamentos e pacientes insatisfeitos com os serviços de saúde oferecidos pelo SUS. A presença do intermediário não funciona como estímulo para obtenção de pacientes, mas sim como uma opção de trabalho para aqueles profissionais autônomos que não conseguem se manter apenas com pacientes particulares. A maioria desses profissionais se estabelece como pessoa jurídica apenas para viabilizar o acesso aos credenciamentos. As operadoras atuam como "patrões" dos cirurgiões - dentistas, delimitando as normas de conduta e determinando a forma de pagamento pelos serviços odontológicos realizados. O crescimento do setor de Saúde Suplementar afeta a prática odontológica autônoma, transformando o cirurgião - dentista em um "empregado" sem direitos trabalhistas, remunerado, exclusivamente, segundo a sua produção. 2, 6, 58 
As mudanças que estão ocorrendo no mercado de trabalho do cirurgião-dentista estão relacionadas com diversos fatores. 0 desenvolvimento da Odontologia Suplementar favorece o surgimento de mais uma opção de trabalho "assalariado" para o cirurgião-dentista, principalmente em períodos de perda do poder aquisitivo da população. A regulação do setor de Saúde Suplementar pelo Estado é um importante aspecto, considerando que os interesses capitalistas podem suplantar os direitos sociais. 
3 Objetivos 


\section{Objetivos}

\subsection{OBJetivo GeRAL}

Obter dados sobre a quantidade de odontólogos que atuam conveniados a planos de saúde na cidade de Bauru, SP, sobre como se dão às relações de trabalho entre as operadoras de planos odontológicos e os cirurgiões-dentistas prestadores de serviços a fim de apresentar subsídios para divulgação de orientações sobre os reais benefícios ou malefícios advindos de uma parceria profissional/operadoras resultando, assim, num aperfeiçoamento do atendimento e dos serviços prestados e na elevação do grau de satisfação dos consumidores (profissional e pacientes).

\subsection{OBJetivos EsPeCífICOS}

- Identificar a quantidade de cirurgiões-dentistas que são conveniados a operadoras de planos odontológicos;

- Identificar quais são as operadoras de planos odontológicos que atuam na cidade de Bauru;

- Avaliar o grau de satisfação dos credenciados a operadoras de planos odontológicos. 
4 Método 


\section{MÉTodo}

Para a realização desse estudo foi elaborado, como instrumento de avaliação, um questionário semi estruturado contendo oito perguntas com respostas de múltipla escolha, a fim de avaliar o grau de satisfação dos profissionais quanto ao relacionamento com as empresas operadoras de planos de saúde, dirigido à cirurgiões dentistas que atuavam profissionalmente no município de Bauru, Estado de São Paulo, Brasil.

O município de Bauru, localizado na região centro-oeste do Estado de São Paulo, com uma população estimada em 316.064 habitantes ${ }^{52}$, foi escolhido para ser o celeiro deste estudo devido à suas peculiaridades no que tange à saturação do mercado de trabalho para o cirurgião-dentista. Possui três faculdades de odontologia que graduam anualmente 230 profissionais $^{24}$, diversos cursos de pós-graduação oferecendo uma oferta de serviços odontológicos especializados, além de um grande número de profissionais atuantes na cidade (665 segundo o Conselho Regional de Odontologia de São Paulo $^{24}$ e 1.048 segundo o Conselho Federal de Odontologia ${ }^{23}$ ). A Organização Mundial da Saúde preconiza como ideal um cirurgião dentista para cada 1.500 habitantes, em Bauru a relação chega a um cirurgião dentista para cada 476 habitantes se for considerado os dados do Conselho Regional de Odontologia de São Paulo (CROSP), considerando os dados do Conselho Federal de Odontologia (CFO) a situação é ainda pior, um cirurgião dentista para cada 301 habitantes. 
Inicialmente o universo da pesquisa era composto por cem cirurgiões dentistas que atuavam profissionalmente em consultórios privados no município, escolhidos aleatoriamente dentre os 665 cadastrados ${ }^{24}$ numa lista solicitada previamente ao CROSP. A quantidade de indivíduos nessa amostra seria suficiente para a realização de inferências estatísticas com intervalo de confiança de 95\%. Devido a não disponibilidade de tal lista pelo CROSP em tempo hábil, decidiu-se então fazer um sorteio aleatório com o mesmo número de entrevistados decididos anteriormente, dentre os nomes contidos nas páginas amarelas da seção cirurgião-dentista de um catálogo telefônico de grande circulação na cidade.

As entrevistas eram realizadas pelo próprio pesquisador nos endereços contidos na lista. Constatou-se pouco interesse por parte dos profissionais cirurgiões-dentistas escolhidos para compor a amostra em participar do estudo, alguns foram visitados várias vezes sem sucesso. Muitos profissionais alegaram falta de tempo para participar da entrevista, mesmo após serem informados que a mesma demoraria menos que cinco minutos. Essa intercorrência fez com que a amostra passasse a ser escolhida por conveniência, isto é, foram entrevistados todos aqueles que aceitaram em participar do estudo, não existindo nenhuma sistemática para a escolha dos participantes. Os profissionais eram abordados e caso consentissem eram entrevistados até um número próximo de cem participantes.

Dessa maneira noventa e um cirurgiões dentistas foram entrevistados e os dados, embora considerados pouco representativos face ao problema 
enfrentado, foram tabulados no programa Microsoft Excel do Windows XP e serão apresentados de forma descritiva, constando de cálculos de proporções percentuais de todas as perguntas, mostrando o perfil da população entrevistada. 
5 Resultados e Discussão 


\section{Resultados e Discussão}

Foram obtidos noventa e um questionários que permitiram o levantamento das seguintes informações:

Tabela 1 - Distribuição dos odontólogos entrevistados no município de Bauru, SP, segundo vínculo com as operadoras de planos de saúde, 2004.

\begin{tabular}{lrr}
\hline Vínculo & $\begin{array}{r}\text { Freqüência } \\
\text { absoluta }\end{array}$ & $\begin{array}{r}\text { Freqüência } \\
\text { relativa }\end{array}$ \\
\hline Sim & 52 & $57,1 \%$ \\
Não & 39 & $42,9 \%$ \\
\hline TOTAL & 91 & $100,0 \%$ \\
\hline
\end{tabular}

Observa-se na tabela 1 que a maioria dos entrevistados $(57,1 \%)$ trabalha com algum tipo de operadora de planos de saúde. Apesar desse resultado não poder ser estendido para todo o universo de profissionais odontólogos devido à constituição da amostra, está de acordo com o resultado de outros trabalhos do gênero. SERRA e HENRIQUES ${ }^{53}$ encontraram 56,69 \% de profissionais trabalhando com operadoras de planos de saúde, a partir de entrevistas com cirurgiões-dentistas durante o 18. ${ }^{\circ}$ Congresso Internacional de Odontologia de São Paulo, realizado no período de 25 a 30 de janeiro de 1998, em São Paulo, SP. ZIMMERMANN E PINHEIRO $^{59}$ obtiveram dados que demonstraram que 53,1 \% dos profissionais odontólogos que atuavam na cidade de Recife, PE, realizando 
tratamento endodôntico, atendiam clientes vindos por intermédio de operadoras de planos de saúde.

Apesar dos resultados encontrados neste trabalho estarem em consonância com a literatura levantada, acredita-se que o número de profissionais que trabalham com operadoras de planos de saúde no município de Bauru, SP, seja bem maior do que o encontrado, devido a própria composição da amostra, pois os profissionais que concordaram em participar das entrevistas são, na sua maioria, recém-formados, indivíduos colaboradores, talvez por terem saído a pouco tempo das universidades e ainda consideram importante a participação em pesquisas científicas. Outro motivo importante é o não credenciamento de recém-formados pelas operadoras de planos de saúde, situação relatada na tabela 3 e também observada por BERGAMASCHI JR. ${ }^{8}$

Foram citados durante as entrevistas o nome de 14 operadoras de planos de saúde, listados na tabela 2, no entanto, também devido a amostra ter sido composta por conveniência, acredita-se que existam mais operadoras atuando no município de Bauru, SP. ZIMMERMANN e PINHEIRO $^{59}$, BELARDINELLI ${ }^{7}$ e CALVIELLI $^{21}$ acreditavam, durante a realização de seus estudos, que os odontólogos tendiam a citar, em entrevistas, apenas os nomes das operadoras que melhor remuneravam e, por isso mesmo, as mais procuradas pelos cirurgiões-dentistas. Outra hipótese era que as operados mais citadas eram as que mais facilitavam o 
credenciamento dos profissionais, ou seja, aquelas em que o tempo de formado e possuir pós-graduação não são critérios para o credenciamento. Após os autores fazerem a comparação dos valores contidos em diferentes tabelas utilizadas pelas operadoras e dos critérios para o credenciamento, afirmaram que são elas que escolhem quais profissionais irão credenciar e ditam as normas da relação que se estabelece, sem nenhuma metodologia específica.

Tabela 2 - Operadoras de planos de saúde citadas pelos odontólogos entrevistados no município de Bauru, SP, 2004.

\begin{tabular}{cl}
\hline 1 & Bradesco \\
2 & Contrato particular com empresa \\
3 & Correios \\
4 & Dentalcorp \\
5 & Embratel \\
6 & Fundação CESP \\
7 & FUNCEF \\
8 & Hamamelis \\
9 & INPAO \\
10 & Interodonto \\
11 & Odontoprev \\
12 & Prevident \\
13 & Sind. Comércio \\
14 & Sudameris \\
\hline
\end{tabular}


Tabela 3 - Distribuição dos odontólogos entrevistados no município de Bauru, SP, segundo motivo do não credenciamento às operadoras de planos de saúde, 2004.

\begin{tabular}{lrr}
\hline Motivos & $\begin{array}{r}\text { Freqüência } \\
\text { absoluta }\end{array}$ & $\begin{array}{r}\text { Freqüência } \\
\text { relativa }\end{array}$ \\
\hline Baixa remuneração & 12 & $30,8 \%$ \\
Falta de tempo & 2 & $5,1 \%$ \\
Ambos & 3 & $7,7 \%$ \\
Burocracia para credenciar & 14 & $35,9 \%$ \\
Burocracia (papelada) & 2 & $5,1 \%$ \\
Recém formado & 2 & $5,1 \%$ \\
Só credenciam especialistas & 2 & $5,1 \%$ \\
Demora no pagamento & 1 & $2,6 \%$ \\
Interferência no plano de & 1 & $2,6 \%$ \\
tratamento & & \\
\hline TOTAL & 39 & $100,0 \%$ \\
\hline
\end{tabular}

A tabela 3 mostra os motivos pelos quais os profissionais entrevistados não trabalham com operados de planos de saúde. O excesso de burocracia para o credenciamento e o fato das operadoras não credenciarem recém-formados e profissionais que não têm especialidades, são os motivos que mais profissionais citaram (46,1 \%). Esse resultado mostra claramente que os odontólogos na ânsia de viabilizar economicamente seus consultórios necessitam cada vez mais se submeter às operadoras e, na primeira oportunidade, aumentarão o contingente de cirurgiões-dentistas conveniados. ${ }^{53,55}$

Segundo RODRIGUES ${ }^{50}$, o profissional autônomo plenamente estabelecido no mercado de trabalho não tem necessidade de muitos 
atendimentos para ganhar o suficiente para garantir a sua qualidade de vida. O cirurgião - dentista que trabalha com intermediários teria que atender mais pacientes, considerando que as tabelas de preço usadas são muito defasadas. Esse fato faz concluir que trabalhar com intermediários aumenta o faturamento em função de uma não ocorrência do paciente particular convencional. A maioria dos pacientes particulares que têm capacidade aquisitiva ou formas de pagamento pelos serviços odontológicos passaram a ser usuários de algum tipo de plano de assistência odontológica, ampliando o seu acesso à saúde bucal. Além disso, alguns setores da população que não possuem esse benefício como salário indireto passaram a recorrer aos intermediários para resolver os respectivos problemas de assistência odontológica.

A tabela 4 mostra claramente que dentre os profissionais credenciados às operadoras de planos de saúde o fazem, em sua grande maioria (86,5\%), para aumentar sua receita e / ou para preencher horários ociosos. Isto comprova a situação difícil do mercado de trabalho em odontologia no Brasil, especificamente no município de Bauru, SP, principalmente para os consultórios e clínicas privadas. 
Tabela 4 - Distribuição dos odontólogos entrevistados no município de Bauru, SP, segundo motivo do credenciamento às operadoras de planos de saúde, 2004.

\begin{tabular}{lrr}
\hline Motivos & $\begin{array}{r}\text { Freqüência } \\
\text { absoluta }\end{array}$ & $\begin{array}{r}\text { Freqüência } \\
\text { relativa }\end{array}$ \\
\hline Aumentar a receita & 10 & $19,3 \%$ \\
Preencher horários & 5 & $9,6 \%$ \\
Ambos & 30 & $57,7 \%$ \\
Procura da clientela & 5 & $9,6 \%$ \\
Indicação de colegas & 1 & $1,9 \%$ \\
Para ter fixo mensal & 1 & $1,9 \%$ \\
\hline TOTAL & 52 & $100,0 \%$ \\
\hline
\end{tabular}

Esta situação tende a se agravar com o aumento na já existente pletora de profissionais e com o grande número de novas faculdades de odontologia e ampliação de novas vagas nos cursos já existentes.

Tabela 5 - Distribuição dos odontólogos entrevistados no município de Bauru, SP, segundo a situação do fluxo da clientela particular no consultório após o credenciamento às operadoras de planos de saúde, 2004.

\begin{tabular}{lrr}
\hline Clientela & $\begin{array}{r}\text { Freqüência } \\
\text { absoluta }\end{array}$ & $\begin{array}{r}\text { Freqüência } \\
\text { relativa }\end{array}$ \\
\hline Aumentou & 23 & $44,2 \%$ \\
Diminuiu & 2 & $3,9 \%$ \\
Não se alterou & 15 & $28,8 \%$ \\
Não sabe & 12 & $23,1 \%$ \\
\hline TOTAL & 52 & $100,0 \%$ \\
\hline
\end{tabular}


A tabela 5 mostra que $44,2 \%$ dos profissionais entrevistados relataram que, desde sua associação com as operadoras de planos de saúde houve um aumento do fluxo de clientes particulares em seus consultórios.

Os primeiros pacientes, geralmente, são pessoas conhecidas (familiares e amigos), que podem fazer uma propaganda indireta do profissional. Quando o mercado de trabalho é favorável, ou seja, quando não existem tantos profissionais para dar cobertura a uma determinada área, o cirurgião-dentista, progressivamente, vai ficando conhecido pelo seu trabalho e se estabelecendo definitivamente no mercado. A grande maioria dos cirurgiões - dentistas é formada para atuar no mercado de trabalho como autônomo. Acontece, entretanto, que nos grandes centros existe uma concentração de profissionais que precisam trabalhar para garantir sua sobrevivência. Quando aquele profissional autônomo sai da fase do atendimento de conhecidos, ele fica em um espaço vazio se não conseguir alguma via que canalize pacientes para o seu estabelecimento. Às vezes, esse problema é resolvido por um colega mais antigo que encaminha pacientes para ele. Na prática odontológica, nem sempre existe esse companheirismo entre colegas. Essa situação ocorre, geralmente, quando existe algum grau de parentesco entre os profissionais. Nesse contexto, é comum o cirurgião - dentista entrar no esquema dos intermediários, perdendo sua autonomia, mas garantindo um fluxo de pacientes que poderia aumentar sua clientela particular e proporcionar-Ihes uma renda satisfatória. 
Segundo SILVA ${ }^{54}$, na verdade o cirurgião-dentista não costuma trabalhar com cálculo de custos nos consultórios, este cobra altos valores dos clientes particulares, muito diferentes do que recebe das operadoras. Acha que, como as operadoras proporciona um fluxo maior de clientes pode receber pouco por isso e, como os clientes particulares são poucos cobra muito por procedimentos. Essa realidade faz que o cliente prefira pagar as operadoras para ser atendido pelo profissional do que diretamente a estes. É real o crescente número de clientes filiados à operadoras de planos de saúde e, devido aos altos valores cobrados pelos odontólogos para o atendimento particular, fica mais difícil não se submeter aos mesmos. ${ }^{29,33,44}$

Segundo RODRIGUES ${ }^{50}$, a presença do intermediário não funciona como estímulo para obtenção de pacientes, mas sim como uma opção de trabalho para aqueles profissionais autônomos que não conseguem se manter apenas com pacientes particulares.

Apesar da grande adesão dos profissionais entrevistados às operadoras de planos de saúde, na tabela 6 , pode-se verificar que $71,2 \%$ não estão contentes com os valores dos procedimentos clínicos repassados pelas operadoras classificando-os como regular ou ruim. Na medida em que esse sistema remunera pelos valores mais baixos do mercado, e autorizam a execução dos procedimentos de acordo com o entendimento de seus administradores, que muitas vezes não são profissionais da área, e sem a participação de um cirurgião-dentista operacional ou das entidades de 
classe, leva os profissionais que atendem os clientes vindos por intermédio das operadoras a perderem sua liberdade para realizar os tratamentos em consonância com o Código de Ética Odontológica, uma vez que estes passarão a realizar somente os procedimentos autorizados e, por isso mesmo, superestimarão os planos de tratamento, realizando procedimentos que muitas vezes não seriam necessários. ${ }^{7,25,33,44}$ Segundo FALCÃO et al ${ }^{31}$ esse procedimento tem sérias implicações éticas e influencia na qualidade e satisfação de mercado que, se não bem avaliados e controlados, implicarão em péssimos relacionamentos operador / prestador / consumidor.

Tabela 6 - Distribuição dos odontólogos entrevistados no município de Bauru, SP, segundo a satisfação com as tabelas de valores utilizadas pelas operadoras de planos de saúde, 2004.

\begin{tabular}{lrr}
\hline Satisfação & $\begin{array}{r}\text { Freqüência } \\
\text { absoluta }\end{array}$ & $\begin{array}{r}\text { Freqüência } \\
\text { relativa }\end{array}$ \\
\hline Ótima & 0 & $0,0 \%$ \\
Boa & 15 & $28,8 \%$ \\
Regular & 28 & $53,8 \%$ \\
Ruim & 9 & $17,4 \%$ \\
Não cobre gastos & 0 & $0,0 \%$ \\
\hline TOTAL & 52 & $100,0 \%$ \\
\hline
\end{tabular}

Parece que as operadoras de planos de saúde representam uma boa alternativa ao insucesso na carreira causado pela escassez da clientela. A tabela 7 mostra que $73,1 \%$ dos profissionais entrevistados vinculados às operadoras se mostram satisfeitos com esse relacionamento. Outro dado 
curioso é que $100 \%$ dos entrevistados que se dizem insatisfeitos com esse relacionamento não pretendem se desligar das operadoras, pois segundo eles, de qualquer maneira existe um incremento na renda do consultório.

Tabela 7 - Distribuição dos odontólogos entrevistados no município de Bauru, SP, segundo a satisfação quanto ao vínculo com as operadoras de planos de saúde, 2004.

\begin{tabular}{lrr}
\hline Satisfação & $\begin{array}{r}\text { Freqüência } \\
\text { absoluta }\end{array}$ & $\begin{array}{r}\text { Freqüência } \\
\text { relativa }\end{array}$ \\
\hline Satisfeitos & 38 & $73,1 \%$ \\
Insatisfeitos & 14 & $26,9 \%$ \\
\hline TOTAL & 52 & $100,0 \%$ \\
\hline
\end{tabular}

SILVEIRA e OLIVEIRA $^{55}$, SERRA e HENRIQUES ${ }^{53}$ e ZIMMERMANN $^{59}$ encontraram resultados opostos em seus trabalhos, neles a grande maioria dos profissionais estão insatisfeitos com o relacionamento com as operadoras.

O excesso de profissionais atuantes no município de Bauru, SP, parece fazer com que, na ânsia de começar ou aumentar o fluxo de clientes no consultório, o cirurgião-dentista busque vínculo com operadoras de planos de saúde. Os clientes advindos das operadoras dão aos profissionais uma falsa impressão de um consultório movimentado e conseqüente satisfação com o relacionamento com as operadoras. Percebe-se também 
que, segundo esses resultados, os profissionais não estão fazendo cálculos de custos do exercício profissional e, conseqüentemente, estar atendendo a muitos clientes de operadoras cujos valores repassados não cobrem os valores mínimos necessários para a realização dos tratamentos, e não estar atendendo a um número maior de pacientes particulares porque em algumas situações cobra preços excessivamente elevados e fora da realidade econômica local.

A tabela 8 mostra que $86,5 \%$ dos profissionais entrevistados disseram que as operadoras atuantes no município de Bauru, SP, não interferem nos planos de tratamento propostos aos clientes. Esse resultado pode ser explicado pelo fato dos profissionais já há algum tempo trabalharem com as operadoras, isto faz com que eles já saibam os procedimentos autorizados ou não pelas mesmas, levando-os a traçarem os planos de tratamento de acordo com o perfil de cada operadora e não de cada cliente.

Tabela 8 - Distribuição dos odontólogos entrevistados no município de Bauru, SP, segundo sua opinião sobre a existência ou não de interferência das operadoras de planos de saúde nos planos de tratamento, 2004.

\begin{tabular}{lrr}
\hline Interferência & $\begin{array}{r}\text { Freqüência } \\
\text { absoluta }\end{array}$ & $\begin{array}{r}\text { Freqüência } \\
\text { relativa }\end{array}$ \\
\hline Interferem & 7 & $13,5 \%$ \\
Não interferem & 45 & $86,5 \%$ \\
\hline TOTAL & 52 & $100,0 \%$
\end{tabular}


Segundo FALCÃO ${ }^{31}$ os profissionais afirmam que as operadoras interferem em seus planos de tratamento e nos procedimentos odontológicos.

O jornal da Associação Brasileira de Odontologia $(A B O)$ da Bahia ${ }^{4}$ de julho de 2004 traz uma reportagem sobre o movimento deflagrado pela classe odontológica contra os honorários praticados e restrições dos procedimento pelas operadoras de planos de saúde. Relatam que algumas operadoras ao invés de contratarem auditores para o acompanhamento dos tratamentos, estão utilizando o expediente da auditoria radiográfica, expondo pacientes aos Raios- $X$, de forma desnecessária. Tal procedimento vai de encontro a portarias da Agência Nacional de Saúde que vedam a utilização de radiografias, salvo para confirmação diagnóstica. Esse relato é um exemplo de interferência das operadoras na rotina do odontólogo.

RODRIGUES ${ }^{50}$ afirma que as operadoras atuam como "patrões" dos cirurgiões - dentistas, delimitando as normas de conduta e determinando a forma de pagamento pelos serviços odontológicos realizados. O crescimento do número de operadoras de planos de saúde afeta a prática odontológica autônoma, transformando o cirurgião - dentista em um "empregado" sem direitos trabalhistas, remunerado, exclusivamente, segundo a sua produção.

Em relação ao prazo de pagamento praticado pelas operadoras, segundo a tabela $9,48,0 \%$ dos entrevistados se dizem satisfeitos e $25,0 \%$ 
o classificam como muito bom ou bom. Mais uma vez nota-se que os profissionais não trabalham com custos de procedimentos e, tem-se a impressão de que ter algo a receber, não importa quando nem quanto, satisfaz os odontólogos. O pagamento pelas operadoras deveria ser considerado como reembolso, uma vez que o procedimento já foi realizado e todos os custos agregados a este já foram contabilizados. Os profissionais tendem a achar mais importante o caixa de entrada do que o de saída, o saldo dessa conta parece ser ignorado ou subestimado.

Tabela 9 - Distribuição dos odontólogos entrevistados no município de Bauru, SP, segundo sua avaliação quanto aos prazos de pagamento dos procedimentos pelas operadoras de planos de saúde, 2004.

\begin{tabular}{lrr}
\hline Avaliação & $\begin{array}{r}\text { Freqüência } \\
\text { absoluta }\end{array}$ & $\begin{array}{r}\text { Freqüência } \\
\text { relativa }\end{array}$ \\
\hline Muito Bom & 3 & $5,8 \%$ \\
Bom & 10 & $19,2 \%$ \\
Satisfatório & 26 & $50,0 \%$ \\
Ruim & 12 & $23,1 \%$ \\
Péssimo & 1 & $1,9 \%$ \\
\hline TOTAL & 52 & $100,0 \%$ \\
\hline
\end{tabular}

Apesar de grande parte dos profissionais relatarem que a procura por operadoras de planos de saúde se faz para o incremento da renda em seus consultórios, a tabela 10 mostra que, segundo os entrevistados, a remuneração por elas representa menos que $50 \%$ da renda dos consultórios para 86,5 \% dos entrevistados. Segundo SERRA E HENRIQUES $^{53}$, ZIMMERMANN e PINHEIRO ${ }^{59}$ e SILVEIRA E OLIVEIRA ${ }^{55}$ 
apesar do aumento da clientela circulante no consultório promovida pelas operadoras, os valores repassados por elas não são significantes.

Tabela 10 - Distribuição dos odontólogos entrevistados no município de Bauru, SP, segundo a representação da remuneração pelas operadoras de planos de saúde na renda mensal do consultório, 2004.

\begin{tabular}{lrr}
\hline Remuneração & $\begin{array}{r}\text { Freqüência } \\
\text { absoluta }\end{array}$ & $\begin{array}{r}\text { Freqüência } \\
\text { relativa }\end{array}$ \\
\hline Mais que $50 \%$ & 7 & $13,5 \%$ \\
Menos que 50 \% & 45 & $86,5 \%$ \\
\hline TOTAL & 52 & $100,0 \%$ \\
\hline
\end{tabular}

As mudanças que têm ocorrido no mercado de trabalho do cirurgião dentista fazem surgir estudos com a finalidade de avaliar as causas e as conseqüências desse processo. Os intermediários, aos poucos, foram conquistando espaço na área odontológica. Atualmente, é mais comum o profissional trabalhar com as operadoras de planos de saúde do que sem elas. Avaliar algumas influências que esses intermediários exercem na prática odontológica é fundamental para uma melhor qualidade de vida para todos os envolvidos. 
6 Conclusão 


\section{CONCLUSÃo}

A análise dos dados obtidos permitiu concluir que:

- A maioria dos entrevistados utiliza a complementação de clientela por intermédio de alguma operadora de planos odontológicos;

- Várias operadoras atuam no município de Bauru - SP, no entanto existem várias outras que não foram citadas pelos entrevistados;

- Os cirurgiões-dentistas entrevistados estão satisfeitos com sua participação no sistema de odontologia suplementar. Dentre os que não estão, nenhum pretende se desligar, pois, de qualquer maneira existe uma complementação de renda em seus consultórios. 
7 Considerações Finais 


\section{CONSIDERAÇÕES FINAIS}

A prática odontológica do profissional autônomo é afetada pelo crescimento do setor de Saúde Suplementar, principalmente, em seus processos, ou seja, nos diversos tipos de relações humanas desenvolvidas dentro da estrutura que dá suporte ao atendimento odontológico. A relação profissional - paciente sofre grande interferência do intermediário. Em geral, existe um descontentamento, por parte dos cirurgiões - dentistas, com os valores de preços das tabelas utilizadas pelas operadoras. Parece que aumentar rendimentos e ter um fluxo de pacientes maior e garantido são as supostas vantagens que fazem com que inúmeros profissionais procurem se relacionar com as operadoras de planos de saúde.

A crise no modelo liberal da profissão, representada por consultórios particulares, deverá exigir desses profissionais uma reavaliação na forma de organização e filosofia de atendimento.

As mudanças que se delineiam para o futuro no mercado odontológico devem considerar a participação decisiva da chamada odontologia suplementar representada pelas operadoras.

Aos profissionais cabe o conhecimento da funcionalidade do setor para assim terem o poder decisório de optar ou não pelo vínculo com as operadoras. 
Às empresas a necessidade de equacionar seus interesses sem perder de vista as reivindicações dos profissionais que efetuam o atendimento.

E a todos uma maior integração, resultando assim em maior qualidade de atendimento, melhoria dos serviços prestados, e elevação do grau de satisfação dos consumidores, lê-se aqui usuários e cirurgiõesdentistas. 
Referências Bibliográficas 


\section{REFERÊNCIAS BIBLIOGRÁFICA ${ }^{\ddagger}$}

1. AGÊNCIA NACIONAL DE SAÚDE SUPLEMENTAR. Informações em Saúde Suplementar. Relatório Nacional Competência de Agosto de 2004. Disponível na Internet: http://www.ans.gov.br/portal/site/perfilgestores/caderno-gest.asp 08 de dezembro de 2004.

2. AGÊNCIA NACIONAL DE SAÚDE SUPLEMENTAR. Regulação e Saúde: Planos Odontológicos: uma abordagem econômica no contexto regulatório. Rio de Janeiro: Ministério da Saúde, Série Regulação e Saúde, v. 2, 272 p., 2002.

3. ALMEIDA, C. O Mercado Privado de Serviços de Saúde no Brasil: Panorama Atual e Tendências da Assistência Médica Suplementar. Texto para discussão - IPEA, Brasília, n. 599, 81 p., nov., 1998.

4. ASSOCIAÇÃO BRASILEIRA DE ODONTOLOGIA. Movimento dos dentistas X planos odontológicos: Unidade e mobilização traduzidas em vitória. Jornal da ABO, p. 4-5, jul., 2004.

5. BAHIA, L. Mudanças e Padrões das Relações Público - Privado: Seguros e Planos de Saúde no Brasil. Rio de Janeiro, 1999, 351 p., Tese (Doutorado em Saúde Pública) Escola Nacional de Saúde Pública da Fundação e Instituto Oswaldo Cruz.

\footnotetext{
${ }^{\ddagger}$ Normas recomendadas para uso no âmbito da Universidade de São Paulo, com base no documento "Referências Bibliográficas: exemplos", emanado do Conselho Supervisor do Sistema Integrado de Bibliotecas da USP, em reunião de Setembro de 1990.
} 
6. BARBOSA, G.M.S. Obrigatoriedade da Odontologia nos Planos de Referência (Ampliação da Oferta?). Projeto apresentado ao Ministério da Saúde, Agência Nacional de Saúde Suplementar, 19 p., Julho, 2003.

7. BELARDINELLI, V.H. Clinica particular: necessidade e possibilidade de fazê-la crescer: as dificuldades atuais. Odontólogo Moderno, v. 14, n. 1, p. 41-50, jan./fev., 1987.

8. BERGAMASCHI JUNIOR, E. Cooperativas e convênios odontológicos privados: uma análise na 9. ${ }^{a}$ região administrativa do Estado de São Paulo. Araçatuba, 158p., 2001. Dissertação (Mestrado) - Faculdade de Odontologia, Universidade Estadual Paulista "Julio de Mesquita Filho" - UNESP.

9. BRASIL, Ministério da Saúde. Anais da 8. ${ }^{a}$ Conferência Nacional de Saúde. Relatório Final. Brasília, 1987.

10. BRASIL. Congresso Nacional. Constituição da República Federativa do Brasil (1967). Brasília, 1967.

11. BRASIL. Congresso Nacional. Constituição da República Federativa do Brasil (1988). Brasília, 1988. 
12. BRASIL. Lei n. ${ }^{\circ} 6.229$, de 17 de julho de 1975. Dispõe sobre a organização do Sistema Nacional de Saúde. Diário Oficial da União, Brasília, p. 008921, col. 1, 18 jul. 1975.

13. BRASIL. Lei $n .^{\circ} 6.439$, de 10 de setembro de 1977 . Institui o Sistema Nacional de Previdência Social e dá outras providências. Diário Oficial da União, Brasília, p. 011617, col. 1, 2 set. 1977.

14. BRASIL. Lei $n .^{\circ} 8.080$, de 19 de setembro de 1990 . Dispõe sobre as condições para a promoção, proteção e recuperação da saúde, a organização e o funcionamento dos serviços correspondentes e dá outras providências. Diário Oficial da União, Brasília, p. 018055, col. 1, 20 set. 1990 .

15. BRASIL. Lei $n .^{\circ} 8.142$, de 28 de dezembro de 1990 . Dispõe sobre a participação da comunidade na gestão do Sistema Único de Saúde (SUS) e sobre as transferências intergovernamentais de recursos financeiros na área de saúde e dá outras providências. Diário Oficial da União, Brasília, p. 025694, col. 1, 31 dez. 1990.

16. BRASIL. Lei n. ${ }^{\circ} 8.666$, de 21 junho de 1993. Regulamenta o artigo 37, inciso XXI, da Constituição Federal, institui normas para licitações e 
contratos da Administração Pública e dá outras providências. Diário Oficial da União, Brasília, p. 008269, col. 1, 22 jun. 1993.

17. BRASIL. Lei n. ${ }^{\circ} 9.656$, de 3 de junho de 1998. Dispõe sobre os planos e seguros privados de assistência à saúde. Diário Oficial da União, Brasília, p. 000001, col. 1, 4 jun. 1998.

18. BRASIL. Lei . $^{\circ} 9.961$, de 28 de janeiro de 2000. Cria a Agência Nacional de Saúde Suplementar - ANS e dá outras providências. Diário Oficial da União, Brasília, p. 000005, col. 2, 29 jan. 2000. Seção Extra.

19. BRASIL. Medida Provisória n. ${ }^{\circ}$ 1.665, de 4 de junho de 1998. Altera dispositivos da Lei n. ${ }^{\circ}$ 9.656, de 3 de junho de 1998, que dispõe sobre os planos e seguros privados de assistência à saúde, e dá outras providências. Diário Oficial da União, Brasília, p.000002, col. 2, 5 jun. 1998.

20. BRASIL . Medida Provisória n. ${ }^{\circ}$ 1.928, de 25 de novembro de 1999. Cria a Agência Nacional de Saúde Suplementar e dá outras providências.

Diário Oficial da União, Brasília, p. 000013, col. 2, 26 nov. 1999. Seção Extra. 
21. CALVIELLI, I.T.P. Debate da EAP abordará serviços odontológicos e convênios. Jornal da APCD, p. 49, set., 1996.

22. CONSELHO FEDERAL DE MEDICINA. Especialidades. Disponível na Internet: http://www.portalmedico.org.br/ 04 de janeiro de 2005.

23. CONSELHO FEDERAL DE ODONTOlOGIA. Números do CFo. Disponível na Internet: http://www.cfo.org.br 04 de janeiro de 2005.

24. CONSELHO REgionAl dE OdONTOLOGIA dE SÃo PAULO. Estatísticas do CROSP. Disponível na Internet: http://www.crosp.org.br 04 de janeiro de 2005.

25. CORDÓN, J. A. Inserção da Odontologia no SUS - avanços e dificuldades. Brasília, 1998b. 181 f. Tese (Doutorado em Ciências da Saúde) - Faculdade de Ciências da Saúde, Universidade de Brasília.

26. CORDÓN, J. A. Sobre a construção histórica do conceito de odontologia em saúde coletiva. Revista Ação Coletiva, Brasília, v.1, n.1, p. 7-23, jan./mar. 1998. 
27. CORDÓN, J. A. Um marco conceitual na questão das práticas em odontologia. Revista Ação Coletiva, Brasília, v.2, n.4, p. 5-16, out./dez.1999.

28. COVRE, E.; ALVES, L. S. Regulação \& Saúde - Planos Odontológicos: Uma Abordagem Econômica no Contexto Regulatório. Agência Nacional de Saúde Suplementar, Brasília, v.2, 272 p. 2002

29. DANTAS FILHO, S. Perdeu-se muito da velha empatia entre médico e paciente. Revista AMES, n. 46, p. 16-18, ago. 1997.

30. DONNANGELO, M. C. F. Medicina e Sociedade : o médico e seu mercado de trabalho, São Paulo: Livraria Pioneira Editora, 174 p. 1975.

31. FALCÃO et al. Avaliação do grau de satisfação dos credenciados a operadoras de planos odontológicos. Revista do Conselho Regional de Odontologia de Pernambuco. v.4, n. 2, p. 107-116, jul./dez. 2001.

32. FAVARET, P. F.; OLIVEIRA, P. J. de. A universalização excludente reflexões sobre as tendências do sistema de saúde. Dados, v. 33, n. 2, p. 257-283, 1990. 
33. FERREIRA, R.A. O valor da saúde bucal nas empresas. Revista da Associação Paulista de Cirurgiões Dentistas, v.49, p. 96-107, 1995.

34. INSTITUTO BRASILEIRO DE GEOGRAFIA E ESTATÍSTICA - IBGE. Acesso e utilização de serviços de saúde. Departamento de Emprego e Rendimento. Rio de Janeiro. 96p, 2000.

35. INSTITUTO BRASILEIRO DE GEOGRAFIA E ESTATÍSTICA - IBGE. Pesquisa Nacional por Amostra de Domicílios - PNAD 2003. Ministério do Planejamento, Orçamento e Gestão. Brasil, v. 24, 2003.

36. MEDICI, A. C. O setor privado prestador de serviços no Brasil: dimensão, estrutura e funcionamento. Rio de Janeiro. (mimeo), 1989.

37. MENDES, E. V. As políticas de saúde nos anos 80: A conformação da reforma sanitária e a construção da hegemonia do projeto neoliberal. In: MENDES, E. V. (org) Distrito Sanitário: o processo social da mudança das práticas sanitárias do Sistema Único de Saúde. São Paulo - Rio de Janeiro: HUCITEC -ABRASCO, p. 19-91, 1999.

38. MINISTÉRIO DA SAÚDE. Agência Nacional de Saúde Suplementar ANS. Resolução de Diretoria Colegiada n. $^{\circ} 39$, de 27 de outubro 
de 2000. Dispõe sobre a definição, a segmentação e a classificação das Operadoras de Planos de Assistência à Saúde.

39. MINISTÉRIO DA SAÚDE. Agência Nacional de Saúde Suplementar ANS. Resolução de Diretoria Colegiada n. ${ }^{\circ} 65$, de 24 de abril de 2001. Dispõe sobre as sociedades seguradoras especializadas em saúde.

40. MINISTÉRIO DA SAÚDE. Conselho Nacional de Seguros Privados. Minuta. Resolução n. ${ }^{\circ}$ XX, 1998. 54 p. Regulamenta as operadoras de seguros ou planos privados de assistência à saúde, e dá outras providências.

41. MONTONE, J. A regulamentação do setor de saúde suplementar. In: BRASIL, Ministério da Saúde. Agência Nacional de Saúde Suplementar. O impacto da regulamentação no setor de saúde suplementar. Rio de Janeiro: ANS, p. 7 - 372000.

42. NARVAI, C. P. Odontologia e Saúde Bucal Coletiva. 2. ed. São Paulo: Livraria Santos Editora Com. Imp. Ltda, 120 p. 2002.

43. OLIVEIRA, J. A. \& TEIXEIRA, S. M. F. Medicina de Grupo: a Medicina e a Fábrica. In: GUIMARÃES, R. (org) Saúde e Medicina no Brasil: 
contribuição para um debate. 4. ed. Rio de Janeiro: Graal, 296 p. 1984.

44. OTERO, J. Pecado Capital. Revista Fola/oral, n.6, p. 162, 1996.

45. PEREIRA, J.C. Sobre os rumos do sistema educacional brasileiro. Fórum Educacional, Rio de Janeiro (ISAE-FGV), v.1, n.4, p.87-100, out./dez., 1977.

46. PINTO, V. G. Saúde Bucal Coletiva. 4. ed. São Paulo: Santos Livraria Editora, 541 p. 2000.

47. PINTO, V.G. A odontologia às vésperas do ano 2000: diagnósticos e caminhos a seguir. Brasília. Editora santos, 1993.

48. PIOLA, S. F. et al. Tendências do sistema de saúde brasileiro: estudo delph. Brasília: IPEA, 147 p. 2001.

49. RING, M. E. História da Odontologia. 1. ed. São Paulo: Editora Manole Ltda, 1998

50. RODRIGUES, R.C.M. A Odontologia Suplementar no Distrito Federal. Brasília, 2002, 216 p. Dissertação (Mestrado) - Faculdade de Ciências da Saúde, Universidade de Brasília. 
51. RONCALLI, A.G. Os planos e seguros privados de saúde no Brasil: reflexos de uma política liberalizante. Disponível na Internet:http://planeta.terra.com.br/saude/angelonline/artigos/art sauc ol/planos.pdf 10 de outubro de 2004.

52. SÃO PAULO. Bauru - Dados Geográficos. Disponível na Internet. http://www.bauru.sp.gov.br/ 04 de janeiro de 2005.

53. SERRA M.C.; HENRIQUES, C. Participação de cirurgiões-dentistas em empresas de odontologia de grupo. Revista da Associação Brasileira de Odontologia Nacional. v. 8, n. 2, abr./mai., 2000.

54. SILVA, M. Das perícias odonto-legais. In: Conselho Federal de Odontologia. Aspectos éticos e legais do exercício da odontologia. 2. ${ }^{a}$ ed. Rio de Janeiro: Conselho Federal de Odontologia, cap. 12, p. 89-97, 1994.

55. SILVEIRA, J.L.G.C.; OLIVEIRA, V. Experiência e expectativas dos cirurgiões-dentistas com os planos odontológicos. Pesquisa Brasileira de Odontopediatria Clinica Integrada. v.2, n.1, jan./abr. 2002. 
56. SÓRIA, L. M.; BORDIN, R.; FILHO, C. C. L. Remuneração dos Serviços de Saúde Bucal: Formas e Impactos na Assistência. Cadernos de Saúde Pública RJ, v.18, n.6, p. 1551-1559, nov-dez. 2002.

57. SZKLAROWSKY, L. F. Convênios, consórcios administrativos, ajustes outros instrumentos congêneres. Boletim de Direito Municipal, São Paulo, v.16, n. 11, p. 705-708, nov., 2000.

58. ZANETTI, C. H. G. A crise da odontologia brasileira: as mudanças estruturais do mercado de serviços e o esgotamento do modo de regulação curativo de massa. Revista Ação Coletiva, v.2 , n. 3, p. 11-24, jul./set. 1999.

59. ZIMMERMANN, R.D.; PINHEIRO, J.T. Honorários Profissionais do Cirurgião-Dentista que realiza endodontia na cidade do Recife. Estudo Comparativo. Revista do Conselho Regional de Odontologia de Pernambuco, Recife, v.1, n.2, out. 1998. 
Abstract

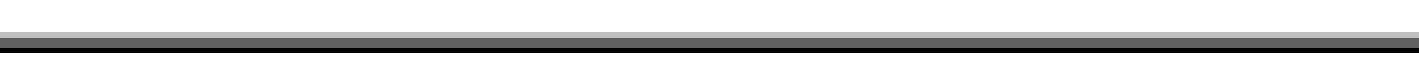




\section{ABstract}

Since the beginning of the history of the plans of health in Brazil, them they had existed without no regulation. Some disequilibrium between the companies who offer the plans, the rendering of services and its users had been detected to the long one of the time. The National Agency of Supplemental Health lode with the objective to promote the defense of the public interest, regulating the operators. With the characterization of Supplemental the Odontology Assistance the odontology companies had appeared, whose main objective seems to be to get the biggest possible profit in a market of services where it has many surgeon-dentists and a great number of people without access to the attendance. The professional sees these events as a chance to perhaps increase its clientele and it's invoicing, causing, in a frantic search for accords that nor always provide ideal conditions for the practical one of the liberal odontology. Ahead of this, this study if he considered to identify, in the city of Bauru-SP, the amount of professionals who are convenction pact the operators of plans of odontology health and which of them act in the city besides evaluating the degree of satisfaction of the credential ones, through a directed questionnaire the 91 professionals chosen for convenience. The results show great part of the professionals are convenction pact or are the wait of a chance to make it. 14 operators had been cited who act in the city, but give credit that they exist more than they had not been cited had the composition of the sample and not the participation of many professionals. To increase incomes and to have 
a bigger and guaranteed flow of patients seem to be the supposed advantages that make with that innumerable professionals look for to become related with the operators of health plans. It exists a satisfaction in working with the operators. The crisis in the liberal model of the profession, represented for particular doctor's offices, will have to demand of these professionals a reevaluation in the organization form and philosophy of attendance. The changes that if delineate for the future in the odontology market must consider the decisive participation of the call supplemental odontologia represented by the operators. A bigger integration fits to all, thus resulting in bigger quality of the attendance and the given services, and in the rise of the degree of satisfaction of the consumers. 
Anexos 


\title{
ANEXO I
}

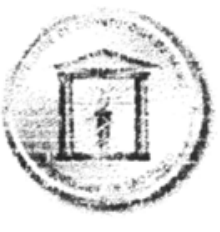

\author{
Universidade de São Paulo \\ Faculdade de Odontologia de Bauru \\ Al. Dr. Octávio Pinheiro Brisolla. 9-75 - Bauru-SP - CEP 17012-901 - C. P. 73 \\ PABX (0XX14)3235-8000 - FAX (0XX14)3223-4679 \\ Comilê de Ética em Pesquisa
}

Processo $n^{\circ}+3 / 2004$

Bauru, 10 de maio de 2004

Senhor Professor,

O projeto de pesquisa encaminhado a este Comitê de Ética em Pesquisa em Seres Humanos, denominado "A relação entre cirurgiões-dentistas e as operadoras de planos de saúde no Município de Bauru-SP”, de autoria de Haroldo José Mendes, que será desenvolvido sob sua orientação, foi enviado ao relator para avaliação.

Na reunião de 28 de abril de 2004 o parecer do relator, aprovando o projeto, foi aceito pelo Comitê, considerando que não existem infrações éticas pendentes.

Informamos que após o envio do trabalho concluido, este Comitê enviará o parecer final, que será utilizado para publicação do trabalho.

Atenciosamente,

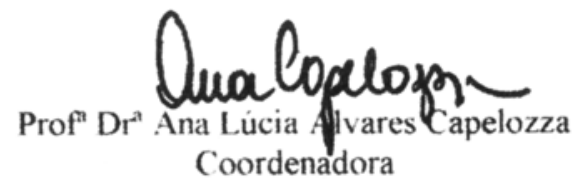

$\mathrm{Ilm}^{\circ} \mathrm{Sr}$. Prof. Dr. José Roberto de Magalhães Bastos

DD. Docente do Departamento de Odontopediatria, Ortodontia e Saúde Coletiva 


\section{ANEXO II}

\section{CARTA DE INFORMAÇÃO}

Prezado(a) Sr.(a)

Apresento-me como cirurgião-dentista, formado pela Faculdade de Odontologia de Bauru, da Universidade de São Paulo, atualmente cursando o mestrado de Odontologia em Saúde Coletiva, pela Faculdade de Odontologia de Bauru, da Universidade de São Paulo.

O objetivo da presente entrevista é coletar informações sobre as relações trabalhistas entre os cirurgiões-dentistas e as operadoras de planos de saúde odontológica.

Solicito sua autorização para o preenchimento do questionário, cuja transcrição dos dados será realizada guardando a confidencialidade e o sigilo ético, sem identificação do entrevistado.

Fica claro que o participante, pode a qualquer momento retirar seu CONSENTIMENTO LIVRE E ESCLARECIDO e deixar de participar desta pesquisa e ciente de que todas as informações prestadas tornaram-se confidenciais e guardadas por força de sigilo profissional (Art. $10^{\circ}$ do Código de Ética Odontológica).

Caso o paciente queira apresentar reclamações em relação a sua participação na pesquisa, poderá entrar em contato com o Comitê de Ética em Pesquisa em Seres Humanos, da FOB-USP, pelo endereço da Al. Dr. Octávio Pinheiro Brisolla, 9-75 (sala no prédio da Biblioteca, FOB/USP) ou pelo telefone (14)3235-8356.

Esperando contar com a sua participação, agradeçemos antecipadamente a colaboração e colocamo-nos a disposição para qualquer esclarecimento.

Atenciosamente,

Prof. Dr. José Roberto de M. Bastos

Orientador

Haroldo José Mendes

Autor

\section{TERMO DE CONSENTIMENTO LIVRE E ESCLARECIDO}

Pelo presente instrumento que atende às exigências legais, o Sr. (a) portador

da cédula de identidade após leitura minuciosa da CARTA

DE INFORMAÇÃO, devidamente explicada pelo profissional em seus mínimos detalhes, ciente do procedimentos ao qual será submetido, não restando quaisquer dúvidas a respeito do lido e explicado, firma seu CONSENTIMENTO LIVRE E ESCLARECIDO concordando em participar da pesquisa proposta.

Por estarem de acordo assinam o presente termo.

Bauru-SP, de de 200 


\section{ANEXO III}

UNIVERSIDADE DE SÃO PAULO

FACULDADE DE ODONTOLOGIA DE BAURU

DEPARTAMENTO DE ODONTOPEDIATRIA, ORTODONTIA E SAÚDE COLETIVA

"A relação entre cirurgiões-dentistas e as operadoras de planos de saúde no Município de Bauru - SP"

\section{QUESTIONÁRIO}

Nome:

Data da entrevista:

1. Trabalha com algum tipo de convênio?

$\square \operatorname{Sim}$ qual(is)?

\section{Não}

Porque?:

$\square$ baixa remuneração

falta de tempo

Ambos

Outros (especificar)

2. Você resolveu participar do sistema de odontologia de grupo porque:
aumentar a receita
preencher horários
Ambos
Outros (especificar)

3. Desde à sua adesão ao sistema de odontologia de grupo, a sua clientela particular:
Aumentou
Diminuiu
Não se alterou
Não sei

4. Você acha que a tabela de honorários utilizada pelo sistema de convênios do qual você participa é:
$\square$ ótima
$\square$ boa
$\square$ regular
$\square$ ruim
$\square$ não cobre meus custos (prejuízo) 
5. você está contente com sua participação em sistema de odontologia de grupo?

$\square \operatorname{Sim}$

$\square$ Não

Se não está contente:

$\square$ Pretende desligar-se em breve

$\square$ Não pretende se desligar, pois, de qualquer maneira, há um incremento em sua renda

6. Existe interferência no seu plano de tratamento e/ou procedimentos odontológicos
$\square \operatorname{Sim}$
$\square$ Não

7. Como você avalia o plano de saúde para o qual você trabalha? Quanto a: Autonomia profissional
$\square$ Muito bom
$\square$ bom
satisfatório
$\square$ ruim péssimo

Prazo de pagamento

$\square$ Muito bom $\quad \square$ bom $\square$ satisfatório $\square$ ruim
péssimo

8. Quanto representa a remuneração por convênio sobre a sua renda no consultório

$\square$ mais que $50 \%$

$\square$ menos que $50 \%$ 